(Aus dern physiologischen Institute der Universität Graz.)

\title{
Über die Unterschiedsschwelle im aufsteigenden Teile einer Lichtempfindung.
}

Von

\author{
Dr. R. Stigler, \\ Assistenten am Institute. \\ (Mit 3 Textfiguren.)
}

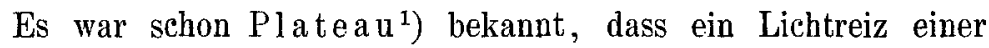
gewissen Zeit bedarf, um das Maximum der Helligkeitsempfindung zu erzeugen; diese Zeit heisst in der einschlägigen Literatur die Maximalzeit. Wirkt der Lichtreiz durch eine kürzere als die Maximalzeit - eine "untermaximale Zeit" - , so erzeugt er auch nur eine untermaximale Helligkeitsempfindung. Wirkt derselbe Lichtreiz auf dieselben oder auf gleich empfindliche Stellen der Netzhaut unter sonst gleichen Bedingungen durch verschieden lange untermaximale Zeiten ein, so erzeugt er auch verschiedene untermaximale Erregungszustände des Sehorganes; ob diese auch mit versehiedenen untermaximalen Helligkeitsempfindungen einhergehen, hängt von der Unterschiedsempfindlichkeit des Sehorganes für derartige Reize ab. Als Unterschiedsschwelle gilt die geringste Differenz zwischen je zwei verschiedenen Einwirkungszeiten desselben Lichtreizes, bei welcher, unter sonst möglichst gleichen Bedingungen, gerade noch zwei verschiedene Helligkeitsempfindungen von einer und derselben oder zwei gleich empfindlichen Stellen der Netzhaut ausgelöst werden. Nach dem Weber'schen Gesetze ist zu erwarten, dass sich die Unterschiedsschwelle im Verlaufe einer Lichtempfindung mit der jeweiligen Helligkeit derselben ändert, also im ansteigenden Teile derselben wächst. Messende Versuche hierüber anzustellen habe ich

1) Plateau, Über einige Eigenschaften der vom Lichte auf das Gesichtsorgan hervorgebrachten Eindrücke. Poggendorff's Ann. Bd. 20 S. 307. 1830. 
mit vorliegender Arbeit unternommen. Ausserdem schien mir die Untersuchung der zeitlichen Unterschiedsschwelle auch Anhaltspunkte für die Bestimmung der Maximalzeit darzubieten.

Über die grossen Schwierigkeiten, die mit solchen Untersuchungen verbunden sind, äussert sich Kries folgendermaassen: „Die Ermittelung von Schwellenwerten ist überall mit nicht geringen methodischen Schwierigkeiten verknüpft, die in letzter Instanz daher rühren, dass der in Betracht kommende psychophysische Mechanismus sich nicht dauernd konstant verhält, sondern in einer weder zu beherrschenden, noch $\mathrm{zu}$ berechnenden Weise wechselt. So kommt es, dass derselbe Unterschied jetzt wahrnehmbar, gleich darauf unwahrnehmbar sein kann oder umgekebrt. Nur in sehr beschränktem Maasse kann man in diesen Erscheinungen eine gewisse Regelmässigkeit bemerken .... Daneben aber spielen rein zufällige Schwankungen eine meistens nicht unbeträchtliche Rolle, und es bedarf daher im allgemeinen sehr zahlreicher Versuche, um zu brauchbaren Ergebnissen zu gelangen." ${ }^{1}$ )

\section{Literaturübersicht und Kritik.}

Die Unterschiedsschwelle für untermaximale Lichtreize von verschiedener Dauer ist schon im Jahre 1893 von K. Petrè $n$ in einer sehr gründlichen und gewissenhaften Arbeit untersucht worden. Da ich dieselbe auffälligerweise in der einschlägigen Literatur nirgends erwähnt gefunden habe, halte ich es für unerlässlich, hier in erster Linie darauf hinzuweisen ${ }^{2}$ ) und daran einige kritische Bemerkungen zu knüpfen. Das Prinzip Petrèn's bestand in der Vergleichung der Helligkeit der oberen und der unteren Hälfte eines in das Gebiet der Fovea fallenden, bei der einen Versuchsreihe weissen, bei der anderen schwarzen Kreises von 50 Min. Durchmesser, welcher auf einem nahezu das ganze Gesichtsfeld erfüllenden mittelgrauen Hintergrunde dargeboten wurde, wobei immer die obere Hälfte um so viel länger exponiert wurde als die untere, dass gerade noch ein Helligkeitsunterschied bemerkt wurde. Die Versuche wurden bei möglichst konstanter Helladaptation bei Tageslicht monokular ausgeführt. Petrèn suchte zuerst die geringste Expositionszeit des ganzen

1) Nagel's Handb. d. Physiol. Bd. 3 [1] S. 21. 1904.

2) K. Petrèn, Untersuchungen über den Lichtsinn. Skandin. Arch. f. Physiol. Bd. 4 S. 421.1893. 
Kreises zu bestimmen, welche überhaupt eine Empfindung Weiss oder Schwarz ergab. Dann untersuchte er in der angegebenen Weise die zeitliche Untersehiedsschwelle, ohne jedoch dadurch seiner Erwartung entsprechend zur Ermittlung der Maximalzeit gelangen zu können, da die länger exponierte obere Hälfte des weissen Kreises niemals dunkler ersehien als die untere. Aus den gefundenen zeitlichen Unterschiedsschwellen konstruierte Petrèn eine Kurve der zeitlichen Unterschiedsempfindlichkeit. Bezüglich der Maximalzeit ergab sich nur, dass sie grösser als 0,3 Sek. sein müsse.

Ein Fehler der Versuchsanordnung Petrèn's, den er selbst erkannt und in seiner Abhandlung als Störung der Kontrolle der richtigen Beobachtung erwähnt hat, ist der Umstand, dass die längere Expositionszeit immer nur der oberen Hälfte des beobachteten Kreises zukam; der Beobachter wasste also im vornhinein, dass eine stärkere Empfindung von Licht, respektive Dunkel, nur in der oberen Hälfte zu erwarten war, wodurch die Unbefangenheit des Urteiles sicherlich erheblich beeinträchtigt wurde. Ein zweiter Fehler der Methode ist der, dass die Erleuchtung, bzw. Verdunkelung nicht im ganzen Reizfelde zugleich und plötzlich mit ganzer Intensität einwirken konnte. Der Durchmesser des als Reizfeld verwendeten Kreises betrug $19,5 \mathrm{~mm}$, die Geschwindigkeit des zur Abblendung des Reizfeldes benutzten Pendels (d. i. dessen hier in Betracht kommender Spaltvorrichtung) bei raschem Gange $21 \mathrm{~mm}$ pro 0,01 Sek., bei dem für grössere Expositionszeiten verwendeten langsameren Gange $6-9 \mathrm{~mm}$ pro 0,01 Sek. Im ersteren Falle dauerte es 19,5/2100 Sek., i. e. 0,0093 Sek., also fast $1 / 100$ Sek., bis der vorangehende Rand des Schirmspaltes das ganze Reizfeld passiert hatte und dieses erleuchtet wurde; im letzteren Falle war hierzu sogar eine Zeit von $19,5 / 600=0,0325$ Sek. erforderlich! Die geringste Breite des Spaltes, die für die Reizschwelle für Weiss erforderlich war, d. h. eben eine Empfindung von grösserer Helligkeit, als der Hintergrund lieferte, betrug, wie Petrèn erwähnt, 2,5 mm, für Schwarz 1,5 mm. - Dementsprechend sollte nach Petrèn's Angaben die Minimalzeit für Weiss 0,025/21 =0,0012 Sek., für Schwarz $0,015 / 21=0,00076$ Sek. betragen. - Allerdings war jeder Raumteil des Reizfeldes während einer solchen Zeit vom verwendeten objektiven Reize getroffen; aber von dem Momente an, wo der Reiz an dem einen Rande des Feldes erschien, bis zu dem Momente, wo er an dem anderen versehwand, verging eine Zeit von fast $1 / 100$ Sek. 
Während dieser Zeit wanderte also ein Lichtstreif von der Breite von etwa 6 Min., resp. ein schwarzer Streifen von der Breite von etwa 4 Min. über das Reizfeld von 50 Min. Durchmesser. -Das ist aber etwas ganz anderes, wie wenn alle Teile des Reizfeldes zugleich während der Zeit von 0,0012, resp. 0,00076 Sek. vom Reiz getroffen worden wären. Wenn also wirklich bei der Reizung mit Weiss bei einer Spaltbreite von $2,5 \mathrm{~mm}$ das ganze Reizfeld zugleich aufleuchtete, was ich aber bezweifeln möchte, so war dies doch nur der Fortdauer der primären Empfindung nach Aufhören des sie erregenden Reizes zu verdanken. Und Analoges gilt auch für die "Reizung" mit Schwarz, über deren Deutung ich mich später äussern will. - Ausserdem ist ja auch anzunehmen, dass die jeweilige Reizung eines Streifens von 6 Min., resp. 4 Min. Breite auch die Nachbarteile dieses eben gereizten Teiles beeinflusste, und es ist ans all diesen Gründen unrichtig, die "Expositionszeit" nach der Breite des Spaltes im Pendel allein zu bestimmen. Jene ist eben in den erwähnten Fällen als viel länger anzusehen, als Petrèn annahm.

Wie verhält es sich nun bei grösseren Spaltbreiten mit der Expositionszeit? Wennes überhaupt einen Augenblick geben sollte, in dem das ganze Reizfeld zugleich vom Reize getroffen wurde, so musste der Spalt eine Breite von mindestens $19,5 \mathrm{~mm}$ haben; in diesem Falle betrug die "Expositionszeit". Petrèn's bei raschem Gange des. Pendels mindestens 0,0093 Sek., bei dessen langsamstem Gange 0,0325 Sek. - Nach Petrèn's Annahme war die Expositionszeit bei einer Spaltbreite $a$ und einer Geschwindigkeit $v=a / v$, in Wirklichkeit aber betrug sie

$$
\frac{a+19,5 \text { (Durchmesser des Reizfeldes) }}{v} \text { Sek.; }
$$

hiervon entfiel für die gleichzeitige Reizung des ganzen Feldes bloss eine Zeit von $\frac{a-19,5}{v}$ Sek., die restierenden $\frac{2 \mathrm{mal} 19 ; 5}{v}$ Sek. gingen für das Ein- und Austreten des Reizes verloren. Dieser Versuchsfehler beeinträchtigt daher die gefundenen Resultate in einer nicht übersehbaren Weise. - Ein dritter Mangel der Versuchsanordnung ist endlich der, dass die objektive Helligkeitsdifferenz zwischen dem Grau im ganzen Gesichtsfelde und den als Reiz verwendeten Flächen von der Intensität des Tageslichtes abhing und somit beständigem Weehsel unterworfen war, was für die Versuchsergebnisse nicht gleichgültig gewesen sein konnte. 
Nun zur Deutung derselben: „Um Empfindung zu erwecken, werden teils helles Weiss, teils Schwarz verwendet" ${ }^{1}$ ), schreibt Petrèn, und da der graue Hintergrund in der Mitte zwischen Weiss und Schwarz lag, so sollten sich nach Petrèn's Postulat sowohl die Minimalzeiten (so bezeichne ich der Kürze halber die geringste zur Empfindung nötige Dauer des objektiven Reizes) als auch die Kurven der zeitlichen Unterschiedsschwellen und die Maximalzeiten für Weiss und Schwarz gleich verhalten. Wo dies nicht zutrifft, dort sucht Petrèn .Versuchsfehler oder Verschiedenheit in der Übung des Experimentators dafür verantwortlich zu machen. Petrèn fasst also seine lichtlose Fläche gerade so als Reiz für das Auge auf wie den weissen Karton. Für die Wahl des grauen Hintergrundes, der in der Zeit zwischen dem Auftreten der Reize auch das Reizfeld ausfüllte, war Petrèn hauptsächlich die Adaptation und die Fixation massgebend. Letzterer Grund wäre heute nicht mehr als stichhaltig $\mathrm{zu}$ bezeichnen, da uns verschiedene Fixationsmarken für Dunkel zur Verfügung stehen, welche die Versuchsresultate nicht wesentlich beeinträchtigen. Die Fragen, welche Petrèn's Versuche über die Minimalzeit zu beantworten hatten, waren in Wirklichkeit folgende:

1. Wie lange mindestens muss die Steigerung einer mittleren Beleuchtungsintensität, von welcher das ganze monokulare Gesichtsfeld erfült ist, innerhalb eines zentralen Bezirkes desselben von 50 Min. Durchmesser um einen gewissen Betrag anhalten, damit sie empfunden werde?

2. Wie lange mindestens muss die Beleuchtung in dem gleichen Bezirke unterbrochen werden, damit der Beobachter diese Unterbrechung empfinde?

Diese beiden Fragen behandeln aber nach meiner Auffassung zwei ganz verschiedene Funktionen des "Lichtsinnes", nämlich die erstere die Empfindlichkeit desselben für Reizzuwüchse, die zweite aber die Andauer der primären Lichtempfindung. Analog verhält es sich mit Petrèn's Untersuchungen über die zeitliche Unterschiedsempfindlichkeit. - Dieselben behandeln die Unterschiedsempfindlichkeit für Zuwüchse der Dauer der Steigerung einer bereits vorhandenen Beleuchtungsintensität, wenn mit Weiss untersucht wurde; bei der Verwendung von Schwarz aber wurde die analoge

1) I. c. S. 429 . 
Funktion im Verlaufe der die Reizung überdauernden primären Empfindung behandelt. - Demnach ergeben sich aus Petrèn's Versuchen folgende Fragestellungen bezüglich der Maximalzeit:

1. Wie lange muss eine das ganze monokulaxe Gesichtsfeld erfüllende mittlere Beleuchtung innerhalb eines zentralen Bezirkes desselben von 50 Min. Durchmesser um einen gewissen Intensitätsbetrag gesteigert werden, damit die stärkste hierdurch mögliche Helligkeitsempfindung zustande komme? Diese Frage behandelt die Maximalzeit einer Reizsteigerung.

2. Wie lange dauert im Zentrum des gleichmässig mittelhellen Gesichtsfeldes die Empfindung der Helligkeit an, wenn an dieser Stelle der Lichtreiz verschwindet, während er im übrigen Gesichtsfelde anbält?

Diese letztere Frage halte ich für unbeantwortbar, weil ich glaube, dass einerseits die verschiedenen Phasen der abklingenden Lichtempfindung und andererseits der Einfluss der Induktion den Moment des völligen Erlöschens der ursprünglichen Lichtempfindung verdecken. Die Induktion spielt übrigens wohl bei dieser ganzen Versuchsanordnung, wobei ein ganz kleiner Bezirk inmitten einer fast das ganze Gesichtsfeld erfüllenden hellen Fläche untersucht werden soll, eine sehr grosse Rolle, welche die Eindentigkeit der Versuchsergebnisse nach meiner Meinung mindestens zweifelhaft macht. Bei Betrachtung der angegebenen Fragestellung, welche sich aus Petrèn's Versuchsanordnungen ergibt, komme ich zur Ansicht, dass uns in seiner Arbeit die Untersuchung von Spezialfällen vorliegt, aus welcher sich allgemeine Schlusse nicht ohne weiteres ableiten lassen. Es liegt mir völlig ferne, den Wert von Petrèn's mühsamen und gründlichen Untersuchungen hiermit schmälern zu wollen: in eindeutiger und über alle Zweifel erhabener Weise werden ja analoge Untersuchungen subjektiver Prozesse wohl nie vollzogen werden können.

Das technische Prinzip der Arbeit Petrèn's, die subjektive Vergleichung zweier benachbarter Lichtreize, von denen der eine kurze Zeit vor dem anderen zu wirken beginnt, aber mit ihm zugleich verschwindet, liegt auch meinen Untersuchungen zugrunde. Zuerst wurde dieses Prinzip von Sigmund Exner ${ }^{1}$ ) angewendet.

1) S. Exner, Über dje zu einer Gesichtswahrnehmung nötige Zeit. Sitzungsber. d. Wiener Akad. d. Wissensch., mathem.-naturw. Klasse Abt. 2 Bd. 58. 1868. 
Bei Exner handelte es sich zunächst darum, die Maximalzeit zu finden. Als Lichtflächen dienten ihm zwei aneinanderstossende Halbkreise. Die zeitliche Differenz im Beginne der beiden Lichtreize bestimmte er so, dass er diese eine sicher übermaximale Zeit wirken und dann den einen Halbkreis gerade um so viel früher erscheinen liess, dass man ihn eben nicht mehr als solchen wahrnahm, d. h. dass man gerade unter der angeführten Bedingung der langen Andauer der beiden Reize nicht mehr bemerkte, dass der eine Halbkreis früher erschienen sei als der andere, sondern den Eindruck hatte, als wäre der ganze Kreis auf einmal erschienen. Die zeitliche Differenz, welche dies gerade noch gestattete, war bei geringeren Intensitäten des Lichtreizes länger als bei grösseren. - Nach Exner's Tabellen war der "Zeitunterschied zwischen Beginn der beiden Kurven" für vier Intensitäten des Lichtreizes, wovon jede folgende das Doppelte der vorhergehenden betrug:

$\begin{array}{ccc}\text { Intensität: } & \begin{array}{r}\text { Zeitunterschied zwischen } \\ \text { I. Versuchsreihe }\end{array} & \begin{array}{c}\text { Beginn der bei } \\ \text { II. Versuchsr }\end{array} \\ 1 & 0,0182 & 0,0193 \\ 2 & 0,0174 & 0,0185 \\ 4 & 0,0174 & 0,0145 \\ 8 & 0,0174 & 0,0169\end{array}$

In jedem Falle war der Zeitunterschied, wie man sieht, ein sehr geringer, zwischen $1 / 50$ und $1 / 60$ Sek. Exner legte besonderes Gewicht darauf, dass die Helligkeit der beiden Reizfelder im Momente jhres Verschwindens verglichen wurde, und dies mit. Recht, weil nach seinen Versuchsergebnissen bei Abdunkelung vor dem Maximum der früher belichteté, bei Abdunkelung nach dem Maximum, also im Abklingen, der später belichtete Halbkreis heller erschien, so dass also theoretisch dasselbe Reizfeld zuerst heller und später dunkler aussehen musste als das mit ihm verglichene, falls die Reizung eine übermaximale Zeit andauerte. Hierzu möchte ich indessen gleich jetzt bemerken, dass während kürzerer Expositionszeiten eine Trennung einzelner Helligkeitsstadien im Verlaufe derselben Empfindung nicht möglich ist; vielmehr erhält man nur einen Gesamteindruck, der durch das höchste erreichte Helligkeitsmaass beherrscht wird; die demselben vorhergegangenen weniger hellen Elementareindrücke gelangen überhaupt nicht zum Bewusstsein, sondern führen in ihrer Gesamtwirkung zu der grössten Helligkeitsempfindung, die eben in der betreffenden Zeit erreicht werden kann. In diesem 
Sinne bezeichnet auch $\mathrm{Ch}$ arpentier ${ }^{1}$ ) die Periode bis zur Maximalwirkung als "Periode de l'addition des impressions élementaires".

Übrigens hat Exner selbst die postulierte Verduṇklung des "übermaximal" exponierten Halbkreises, die er als "negatives Nachbild" bezeichnete, nicht deutlich gesehen; es erschien ihm bloss „immer als ein heller vertikaler Streifen, der durch Kontrast besonders hervortretenden Grenze zwischen dem schwarzen und weissen Halbkreise entsprechend". Exner gelangte mit seiner Methode zu dem Resultate, dass intensivere Lichtreize die maximale Helligkeitsempfindung früher herbeiführen als weniger intensive. Die Maximalzeit des stärksten von Exner untersuchten Reizes betrug 0,1188 Sek., des schwächsten 0,2873 Sek. (als Reiz diente hierbei das Fernrohrbild künstlich beleuchteten weissen Papieres). Zugleich erwähnt auch Exner, dass, wenn das Auge hinlänglich ausgeruht war, schon ein Lichtreiz von 0,0001 Sek. Dauer eine deutliche Empfindung hervorrief.

In der Absicht, das Ansteigen einer Lichtempfindung bis $z u$ ihrem Maximum kennen zu lernen, wurden nach Exner von verschiedenen Autoren Versuche auf Grund des Vergleiches zweier zugleich dargebotener Lichtreize, die sich nur durch ibre Daver unterschieden, angestellt, deren Arbeiten ich, obwohl sie sich nicht auf die zeitliche Untersehiedsschwelle beziehen, hier deshalb anführen muss, weil ich mich im Verlaufe meiner Arbeit mehrmals auf die Versuchsanordnungen dieser Autoren berufen muss.

Mit Exner's Methode versuchte zunächst Lamansky ${ }^{2}$ ) die Maximalzeiten für farbiges licht $\mathrm{zu}$ ermitteln. Sodann hat Kunkel ${ }^{3}$ ) Exner's Versuche mit dessen Apparat wiederholt, jedoch ohne so zu einem Resultate zu gelangen. Es gelang ihm nämlich niemals, „beim Abschneiden der beiden Erregungskurven an Punkten, die sicherlich jenseits des Maximums gelegen waren, die Hälfte des Gesichtsfeldes, welche nur kürzere Zeit sichtbar gewesen war, a uch nur gleich hell, geschweige denn heller zu sehcn als die dem Auge durch längere Zeit dar-

1) A. Charpentier, Recherches sur la persistance des impressions rétiniennes et sur les excitations lumineuses de courte durée. Arch. d'Ophthalmologie t. 10. 1890.

2) S. Lamansky, Über die Grenzen der Empfindlichkeit des Auges für Spektralfarben. Arch. f. Ophthalmol. Bd. 17, S. 123.1871.

3) A. Kunkel, Über die Abhängigkeit der Farbenempfindung von der Zeit. Pflüger's Arch. Bd. 9, S. 197. 1874. 
Über die Unterschiedsschwelle im aufsteig. Teile einer Lichtempfindung. 171

gebotene." ${ }^{1}$ ) Aus dieser Äusserung geht hervor, dass K u n ke l immer, auch bei beliebig langer Dauer der beiden Reize, den länger andauernden auch heller empfunden hat. Dies scheint mir wichtio, und ich werde darauf noch später zurückkommen. Kunkel hat sodann mit dem gleichen Apparat versucht, durch Vergleichung von Lichtreizen von verschiedener Intensität unter Zugrundelegung des Fxner'schen Prinzipes, dass der stärkere Lichtreiz auch steiler ansteige als der schwächere, die Maximalzeit zu bestimmen. Dic hierbei verwendeten zeitlichen Differenzen der beiden Lichtreize betrugen,' wie ich aus Kunkel's Tabellen entnehme, höchstens $\frac{25,5}{1200}=0,021$ Sek. Kunkel untersuchte auf diese Art bloss Spektralfarben. Er erwähnt hierbei selbst als. Fehler der Versuchsanordnung, dass während der Beleuchtung bloss eines Halbkreises des Sehfeldes seines Fernrohres die andere Hälfte nicht ganz dunkel gewesen sei, so dass in dieser letzteren die beabsichtigte Reizung nicht von Nüll, sondern von irgendeinem höheren Werte anstieg.

Als Maximalzeit erhielt er für Rot . . 0,0573 Sek.

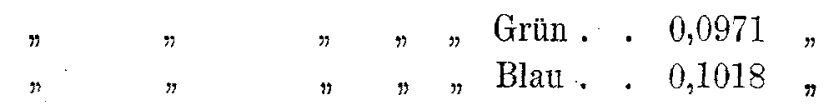

Ferner kommt er nach seinen Versuchen zu der Annahme, dass der erste Teil der Erregungskurve annähernd geradlinig ansteige, und zwar dauere der geradlinige Verlauf um so länger, je grösser die Helligkeit sei. Die Versuche wurden mit dem linken Auge bei Dunkeladaptatiou ausgeführt.

Mit einer anderen Versuchsordnung bat später Charpenti er ${ }^{2}$ ) die Maximalzeiten verschiedener Lichtreize monokular mit Hilfe seines „Photoptometers" zu bestimmen versucht, indem er - und das ist ein prinzipieller Unterschied gegenüber Exner's Methode einen Lichtreiz von variabler kurzer Dauer mit einem kontinuierlichen verglich. Charpentier fand hierbei:

1. dass die Maximalzeit mit der Zunabme der Reizintensität abnehme; für einen schwachen Lichtreiz ergab sich eine Maximalzeit von 0,062 , für einen stärkeren von 0,012 Sek.;

1) 1. c. S. 201, Anm. Wie früher erwähnt, hat auch Petrèn keine Verdunklung gesehen.

2) 1. c. Hiervon ein kurzer Auszug auch bei G. Martius, Über die Dauer der Lichtempfindungen. Beitr. z. Psychol. u. Philos. von G. Martius Bd. 1 H. 3 S. 355 ff. 1902. 
2. dass die durch untermaximale Reize ausgelöste Helligkeitsempfindung der Reizdauer proportional sei, d. h. dass die Empfindungskurve bis zum Maximum geradlinig ansteige.

Es ist nicht meine Absicht, hier eine eingehende Kritik von Charpentier's Arbeit zu geben; nur insoweit die Versuchsanordnung in Betracht kommt, seien folgende einflussreiche Fehler erwähnt:

1. Fs wurde der zu untersuchende kurzdauernde Reiz mit einem konstant dauernden unmittelbar benachbarten verglichen. Abgesehen von dem zu erwartenden Einflusse der simultanen Induktion stösst ein solches Verfahren, wie schon $\mathrm{Kries}^{1}$ ) bemerkt, „jedenfalls schon wegen der bei Dauerbeleuchtung sich stetig ändernden Erregungsstärke" auf erhebliche Bedenken. Ausserdem ist es sicher unvermeidlich, dass in den Reizpausen durch unwillkürliche Augenbewegungen die Netzhautpartie, welche den zeitlich begrenzten Reiz zu empfangen hat, von dem konstanten getroffen wird, so dass ersterer auf eine bereits gereizte Netzhautstelle fällt. Dann ist es aber unzulässig, die gefundenen Zeiten als die Maximalzeiten der verwendeten Reize zu betrachten, da sie höchstens die Maximalzeiten der verwendeten Reizzuwüchse darstellen könnten.

2. Die Reize kehrten viel zu rasch wieder; die Umdrehungszeit der Registriertrommel betrug in einem Falle 0,29, im anceren Falle 0,227 Sek. Da in dieser Zeit sicherlich die Wirkung (Nachbild) eines einzelnen Lichtreizes noch nicht erloschen war, so trat also eine Summation der aufeinanderfolgenden Lichtreize ein. Ich habe beim Durchlesen von Charpentier's Abhandlungen nirgends gefunden, dass dies vermieden wurde.

1893 hat Petrèn seine eingangs besprochene Arbeit publiziert. Ich will an dieser Stelle nachtragen, dass Petrèn Exiner's Zeitangaben für das Maximum einer Lichtempfindung deshalb anzweifelt, weil dieselben mit Beibehaltung einer sehr geringen Differenz der Expositionszeiten gefunden worden seien, während nach Petrèn's Annahme die zeitliche Unterschiedsempfindlichkeit nicht plötzlich von einem hohen Betrage auf Null herabsinken kann. Exner hätte also nach Petrèn's Meinung noch weitere Untersuchungen mit grösserer Differenz der Expositionszeiten anstellen sollen. Ferner sei hier bemerkt, dass Petrèn zuerst der Fixation und der Adap-

1) Nage l's Handb. d. Physiol. Bd. 3 [1] S. 228.1904. 
Über die Unterschiedsschwelle im aufsteig. Teile einer Lichtempñndung. 173

tation die gebührende Aufmerksamkeit bei derartigen Versuchen geschenkt hat.

Sodann haben die Frage der Maximalzeit nahezu gleichzeitig, doch ganz unabbängig von einander, Martius ${ }^{2}$ ) und $D \ddot{u} \mathrm{rr}^{2}$ ) ausführlichst untersucht. Beide behandeln kritisch die ihnen vorliegende Literatur, wobei aber Petrèn's Arbeit keine Erwähnung geschieht. Die Vorteile, die Martius' Apparat gegenüber dem Exner'schen bietet, sind nach Martius hauptsächlich folgende: bequeme Vergleichung zweier Lichteindrücke, die von einander unabhängig zeitlich begrenzt werden; genaue Bemessung der Dauer der Lichteinwirkung und vor allen Dingen eine wirklich augenblickliche Unterbrechung. der letzteren, so dass die Unterbrecbungszeit auch gegenüber den kurzesten Reizzeiten nicht in Betracht kommt.

Die von Martius ermittelten Maximalzeiten betrugen 0,013 Sek. für die grösste und 0,093 Sek. für die kleinste verwendete Intensität, welch letztere $1 / 32$ der ersteren betrug. Ein zweiter Beobachter fand 0,012 und 0,089 Sek. Versuche bei Helladaptation ergaben noch geringere Maximalzeiten. Die bei weitem grösseren Maximalzeiten Exner's $(0,15-0,287$ Sekunde) hält $M$ artius schon deshalb für unrichtig, weil man sonst das Ansteigen einer Lichtempindung beim gewöhnlichen Sehen bemerken müsste. Durch Vergleichung eines konstant dargebotenen geringeren Reizes mit einem untermaximalen grösseren sollte sodann die Anstiegskurve des letzteren bestimmt werden (ähnlich wie bei Exner). Die Resultate dieser Untersuchungen ergaben im Gegensatze zu Charpentier, dass die Lichtwirkung nicht proportional der Zeit und die Anstiegskurve also nicht geradlinig verlaufe, sondern mit der Zeitdauer an Steilheit abnehme; ferner seien die Kurven um so steiler, je grösser die Intensität sei.

Während die früher besprochenen Versuchsanordnungen auf der Vergleichung zweier simultan dargebotener unmittelbar benachbarter Reize berubten, wurden von Martius zwei auf dieselbe Netzhautstelle nach einander fallende Lichtreize verglichen, also mit Zuhilfenahme des Gerlächtnisses für Helligkeiten. - Ich kenne keine exakten Versuche über das Gedächtnis für Helligkeiten; ich weiss

1) G. Martíus, Über die Daner der Lichtempfindungen. Beitr. z. Psychol. u. Philos. von G. Martius Bd. 1 S. 3. 1902.

2) E. Dürr, Über das Ansteigen der Netzhanterregungen. Wundt's philos. Studien Bd. 18. 1903. 
nur aus eigener Erfahrung, dass dasselbe durch Übung gesteigert werden kann, bin aber dennoch davon überzeugt, dass man es nie so weit mit dieser Übung bringen kaun, Helligkeiten, welche nebeneinander kaum mehr unterschieden werden können, aus dem Gedächtnisse mit einander zu vergleichen. Ausserdem ist ja zuerst durch C. F. Müller's ${ }^{1}$ ) und hernach durch Exner's Untersuchungen, sowie auch von seiten anderer Autoren sicher festgestellt worden, dass die durch einen konstanten Lichtreiz erzielte Helligkeitsempfindung nach der Maximalzeit nicht konstant jst, sondern anfangs rascher und dann langsamer abnimmt. Es ist daher nicht möglich, durch Vergleich mit einem durch längere Zeit konstant dargebotenen Reize die Maximalzeit zu bestimmen. Die Frage, welche Martius tatsächlich untersucht hat, war: Wie lange muss ein monokularer Lichtreiz mindestens dauern, damit die durch ihn hervorgebrachte Helligkeitsempfindung von einer durch einen gleichen, aber andauernden Lichtreiz hervorgebrachten, bei rasch a ufeinanderfolgender Vergleichung nicht mehr unterschieden werden kann?

Es wirkte bei dieser Untersuchung der Vergleichsreiz, da „in der Regel nur ein Auge benutzt wurde", nach einer sehr kurzen Pause, die gerade dazu ausreichte, dass das Auge sich von dem einen zu dem anderen Fernrohr wendete, auf dieselbe zentrale Netzhautpartie, welche von dem vorhergehenden Reize getroffen worden und wahrscheinlich noch nicht zur Ruhe gekommen war. Letzteres scheint auch aus Martius' Bemerkung hervorzugehen, dass der Beobachter, wenn sich die positiven Nachbilder unangenehm bemerkbar machten, das Auge zeitweilig schliessen konnte, um es auszuruhen ${ }^{2}$ ). - Ich glaube, dass sich aus diesen beiden Umständen, namentlich aus der geringen Unterscheidungsfähigkeit des Gedächtnisses für Helligkeiten, die geringen "Maximalzeiten " Martius' hinlänglich erklären lassen. Dem Einwurfe Martius' gegen die längeren Exner'schen Maximalzeiten, dass man diese beim gewöhnlichen Sehen wahrnehmen müsste, steht, glaube ich, die Tatsache gegenüber, dass die Reizung beim gewöhnlichen Seben nicht vom Nullpunkte, sondern ron einem viel höheren Werte ansteigt. Die Adaptation ist, wie aus Martius' Angaben hervorgeht, keine bestimmte gewesen.

1) C. F. Müller, Versuche über den Verlauf der Netzhautermüdung. Diss. Zürich 1866.

2) Dieser Versuchsfehler ist auch von Wilhelm Wirth in dessen Referat im Arch. f. d. ges. Psychol. Bd. 1 S. 24 u. 25. 1903 hervorgehoben worden. 
Für den zweiten Teil der Versuche, nach welchen der Verlauf der. Kurve bestimmt werden sollte, wäre es nötig gewesen, die Halbierung der Reizintensitäten möglichst genau vorzunehmen. Ich glaube aber, dáss dies nach der angegebenen Methode nur sehr annäherungsweise möglich ist. Vor allem ist es zu bezweifeln, dass die beiden durch einen doppeltbrechenden Kalkspatkristall erzeugten Lichtbilder von gleicher Helligkeit gewesen sind. Ich habe bei Versuchen mit mehreren Kalkspatprismen jedesmal gefunden, dass die beiden Lichtbilder, welche dieselben lieferten, verschieden hell waren, und diese Beobachtung ist mir auch von anderen Physiologen und Physikern bestätigt worden. Ich habe nicht in Erfahrung bringen können, ob das gegenseitige Intensitätsverhältnis der beiden durch einen Doppelspat gelieferten Lichtbündel experimentell festgestellt worden ist. Ferner aber konnte die Abstufung des Vergleichsreizes, um ihn zu halbieren, durch Vorsetzung von matten oder grauen Gläsern doch nur eine grobe und sprunghafte sein. Diese Abstufung geschah durch einfache Vergleichung eines der durch den Doppelspat gelieferten Kreise mit dem Felde, welches gleich hell gemacht werden sollte. Eine solche subjektive Abschätzung zweier konstanter Lichtreize ist, wie ich bei der Besprechung meiner eigenen Versuchsanordnung noch näher ausführen werde, ungenau und unverlässlich. Aus dem gleichen Grunde halte ich auch die Gleichheit der Lichtquantitäten, welche aus den beiden Fernrohren ins Auge fielen, für nicht erwiesen; sollten diese gleich sein, so müssten durch die verwendeten punktuellen Diaphragmen genau gleiche Lichtquantitäten hindurchgehen und der Veriust derselben durch Reflexion und Absorption in den beiden parallel geschalteten optischen Systemen ebenfalls genau gleich sein. Fehler in dieser Beziehung sind aber wohl unvermeidlich und müssen eben so weit als möglich mit Hilfe anderer Methoden gefunden und korrigiert werden. Allerdings ist anzunehmen, dass der zuletzt erwähnte Fehler bei Martius' Apparat zufolge dessen ausserordentlicher Präzision verschwindend klein war.

Nahezu zugleich mit Martius, und ohne von dessen Arbeit Kenntnis zu haben, hat $\mathrm{D}$ ü rr die Untersuchung der Maximalzeiten vorgenommen, und zwar einerseits für Weiss und für farbige Lichter, andererseits bei Hell- und Dunkeladaptation. Die grosse Differenz zwischen den.Versuchsresultaten Exner's und Kunke]'s schien ihm hauptsächlich in der Nichtbeachtung der Adaptationsverhältnisse; 
andererseits der möglicherweise vorhandenen Einwirkung des Simultankontrastes und der Irradiation zufolge der unmittelbaren Nachbarschaft der beiden Reize begründet zu sein. Demgemäss widmete er von Anfang an diesen beiden Faktoren besondere Aufmerksamkeit, und zwar dem letzteren, indem er die beiden zu vergleichenden Reizfelder durch einen lichtlosen Streifen trennte.

Nachdem mehrere Versuchsanordnungen mit objektiven gleichen Helligkeiten zu keinem brauchbaren Ergebnisse geführt hatten, versuchte es $\mathrm{D}$ ürr mit der Darbietung versehieden heller Reizflächen.

Diese Versuchsanordnung ergab tatsächlich ein Resultat: Es wurde nämlich das grösste objektive Helligkeitsverhältnis vom Normalreiz zum Vergleichsreiz, 27:4, bei einer Einwirkungsdauer des Vergleichsreizes von 0,266 Sek. im Mittel gefunden. Diese Zeit betrachtet Dürr als die Maximalzeit für Weiss bei Dunkeladaptation. Die Helligkeit des hier untersuchten Vergleichsreizes war eine sehr geringe. -- Es wurde sodann die gleiche Untersuchung für homogene farbige Reize von gleicher Helligkeit, welche durch Strahlenfilter erzeugt wurden, angestellt und diese mit einem weissen Normalreize verglichen. Die Farbe dés Vergleichsreizes wurde zufolge der geringen Intensität bei der Dunkeladaptation fast gar nicht empfunden. Die Maximalzeit aller homogenen Farben betrug dabei im Mittel 0,529 Sek.

Sodann stellte Dürr Versuche bei Helladaptation an. Diese ergaben wiederum die gleichen Maximalzeiten wie die früheren, nur war das objektive Intensitätsverhältnis vom maximal wirkenden Vergleichsreiz zu dem ihm subjektiv gleicherseheinenden 2,4 bis 2,8 Sek. wirkenden Normalreiz bei Helladaptation für die einen Beobachter $1: 2$, bei den anderen $2: 5$, bei Dunkeladaptation mit der gleichen Versuchsanordnung 4:23. - Aus diesen Versuchen zog Dür r den wichtigen Schluss, dass die Maximalzeit ganz unabhängig. sei von der Intensität des Lichtreizes und der Adaptation des Auges und für Weiss im Mittel 0,269 Sek., für homogenes farbiges Licht 0,529 Sek. betrage.

Ferner geht aus diesen Versuchen hervor, dass jeder weisse oder homogen farbige Lichtreiz von der Dauer der Maximalzeit und von beliebiger Intensität bei Helladaptation 2, resp. $2^{1 / 2}$ mal so hell erscheine wie nach einer Dauer von $2-3$ Sek., bei Dunkeladaptation $5^{3 / 4}$ mal so bell wie nach einer Daner von $2,3-2,8$ Sek., resp. bei einer anderen Versuchsreihe $6^{3 / 4} \mathrm{mal}$ so hell wie nach einer Dauer von 1,6-1,9 Sek. - Daraus würde weiters hervor- 
gehen, dass das relative Maass der Helligkeitsempfindungsabnahme nach der Maximalzeit (also der „Umstimmung") von der Reizintensität unabhängig sei. Dies ist allerdings auch seinerzeit von C. F. Müller ${ }^{1}$ ) angegeben worden. Kries ${ }^{2}$ ) aber hat dieses Resultat Müller's darauf zurückgeführt, dass dieser mit sehr geringen Differenzen der Reizintensität und nie mit völlig dunkeladaptiertem Auge experimentiert habe. - Kries selbst fand unter Berücksichtigung der letzteren Faktoren im Gegensatze zu Mülle r, dass bei grösserer Reizintensität auch dem relativen Maasse nach die Umstimmung rascher vor sich gehe, oder, wie es Wirth ${ }^{3}$ ) ausdrückt, „dass der Ermüdungskoeffizient bei Erhöhung der Reizintensität hinter der direkten Proportionalität zuerst wenig, damn aber immer mehr zurückbleibe". Damit stehen aber die Ergebnisse von Dürr's Untersuchungen in direktem Widerspruche. Ausserdem fand Kries nach 3 Sek. langer Darbietung einer hellen Fläche bloss eine subjektive Helligkeitsabnahme auf $0,91-0,74$ der anfänglichen Helligkeit, so dass die von Dürr gefandene Abschwächung bis $\mathrm{zu}^{4 / 27}$ der Maximalhelligkeit sehr auffallend ist. Eine so starke Abschwächung fand Kries erst nach $40-160 \mathrm{Sek}$ - Es ist allerdings bei den Versuchen von Kries nicht sicher, ob gerade das Maximum des Vergleichsreizes während des Vergleichsaktes zur Geltung kam. Ausserdem ist der von $\mathrm{Kries}$ dargestellte Verlauf der Umstimmung zufolge einiger von ihm selbst ${ }^{4}$ ) erläuterter Mängel der Versuchsanordnung nicht als unbedingt feststehend zu betrachten. Es gibt aber auch bei der Versuchsanordnung Dürr's manches, was Bedenken erregt und zum mindesten geeignet erscheint, die Sicherheit der Versuchsergebnisse in Frage zu stellen. Der Ausgangspunkt der Versuche war immer die Gleichstellung von Vergleichsreiz und Normalreiz mittelst beliebig langer Betrachtung derselben ohne besondere Hilfsmittel. Von der Unzulängliehkeit dieser photometrischen Methode habe ich mich gelegentlich meiner eigenen Versuche und der meiner Mitbeobachter wiederholt überzeugt. Ferners ist bei Dürr's Versuchen der Adaptationszustand nicht eindeutig bestimmt. Bezüglich

1) 1 . c.

2) Kries, Über Ermüdung des Sehnerven. Gräfe's Arch. f. Ophthalm. Bd. 23 Abt. 2 S. 30 u. 31. 1877. Sieh auch Nagel's Handb. Bd. 3 [1] S. 216.

3) W. Wirth, Der Fechner-Helmholtz'sche Satz über negative Nachbilder und seine Analogien. Wundt's philos. Studien Bd. 16 S. 473.1900.

4) Nagel's Handb. d. Physio:. Bd. 3 [2] S. 261. 
der Helladaptation gelten die bereits von Pe trè è erhobenen Einwürfe, dass während der Versuche dunkeladaptiert wird; dies kommt allerdings wegen der geringen Dauer der Versuche selbst (10-Sek.) nicht wesentlich in Betracht. Aber die Dunkeladaptation war gewiss keine konstante; denn vor Beginn der Versuche wurde durch eine Viertelstunde an völlige Dunkelheit adaptiert: die darauf ebenfalls in völliger Dunkelheit ausgeführten Versuche währten eine Stunde. Aus den von Piper ${ }^{1}$ ) angestellten Versuchen geht aber hervor, dass die Dunkeladaptation in den ersten 10-12 Min. nur sehr langsam, dann aber sehr rasch zunimmt, so dass sie in der ersten Stunde bereits die Hälfte des nach ca. 8 Stunden erreichten Maximums beträgt. Die Versuche Dürr's wurden daher unter fortwährend wechselndem Adaptationszustande angestellt. Dürr gibt allerdings an, dass die Adaptation keinen Einfluss auf die Maximalzeit habe, aber er fand doch bei Helladaptation ein anderes objektives Intensitätsverhältnis zwischen Vergleichs- und Normalreiz als bei Dunkeladaptation. - Es erscheint auffällig, dass bei der Adaptationsveränderung des Auges wäbrend des fünfviertelstündigen Aufenthaltes im Dunkeln dieses Verhältnis konstant war. Sodann war wobl auch die Dauer des Vergleichsreizes zufolge des Mangels eines Regulators der inkonstanten Umdrehungsgeschwindigkeit des Zylinders (resp. der Scheibe) nicht ganz sicherzustellen. Immerhin mag auch der letzte Einwand gegenüber einer grossen Anzahl von Versuchen nicht besonders in Betracht kommen, ebenso wie die wabrscheinlich mangelhafte Homogenität der als Reizfläche dienenden Transparentpapiere. Dass die Versuche mit den durch das Gesichtsfeld wandernden Streifen negativ ausfielen, ist nicht $\mathrm{zu}$ verwundern, ebenso die geringe Ausbeute mit fixen Reizen von gleicher objektiver Intensität, deren einer, der Normalreiz, nahezu 2 Sek. dargeboten und sodann mit dem kurzdauernden Vergleichsreiz verglichen wurde. Die Empfindung, welche der Normalreiz nach 2 Sek. auslöste, war selbstverständlich viel geringer als die Maximalempfindung, so dass auf diese Weise die Maximalzeit nicht gefunden werden konnte. In der Reihe der von $D$ ürr ausprobierten Versuchsanordnungen fehlt aber auffallenderweise gerade die des Vergleiches zweier fixer Reize von gleicher objektiver Intensität mit geringer Differenz der Expositions-

1). H. Piper, Über Dunkeladaptation. Zeitschr. f. Psychol. a. Physiol. d. Sinnesorgane Bd. 31 S. 182. 1903. 
zeiten. Offenbar hat sich $\mathrm{D} u ̈ r r$ durch das Misslingen eines solchen Vergleiches mit wandernden Reizen veranlasst gefühlt, ähnliche Versuche mit fixen Reizen zu unterlassen. Ich will gleich an dieser Stelle bemerken, dass ich den Vergleich zweier von einander durch einen schwarzen Zwischenraum getrennter Kreisflächen von gleicher objektiver Helligkeit bei geringer Differenz der Expositionsdauer versucht habe, dass aber die Unterscheidungsfähigkeit für die dargebotenen untermaximalen Helligkeiten eine so geringe war, dass diese Versuche zu keinem brauchbaren Resultate führten. Wenn man die Tabellen Dürr's betrachtet, so zeigt sich eine ganz beträchtliche Breite der Unterschiedsempfindlichkeit, und die Maximalzeit für Weiss von 0,269 Sek. wurde als Mittel vieler Werte zwischen 0,215-0,311 Sek. berechnet. - Angesichts dessen verweise ich abermals auf den Einwand, den $\mathrm{Kries}^{1}$ ) gegen die Methode der Vergleichung eines sehr kurze Zeit aufleuchtenden Feldes mit einem benachbarten erheblich länger beleuchteten wegen "der bei Dauerbeleuchtung sich stetig ändernden Erregungsstärke" des länger beleuchteten Feldes und zwar ausdrücklich gegen die Methode von Dürr erhebt. - Diesen Einwänden will ich hinzufügen, dass in Dürr's Versuchen weder die Grösse, noch die Lage der gereizten Netzhautbezirke berücksichtigt worden ist; andererseits muss ich aber auch bemerken, dass ich mich durch eigene Versuche davon überzeugt habe, dass die längere Darbietung des einen Reizes die Vergleichung desselben mit einem von ihm räumlich getrennten anderen kurzdauernden bedeutend erleichtert, vermutlich, weil die Aufmerksamkeit nicht mehr im gleichen Maasse für beide Reize während der kurzen Dauer des "Vergleichsreizes" in Anspruch genommen wird, da der länger dauernde "Normalreiz" beim Erscheinen des Vergleichsreizes bereits "aufgefasst" worden ist und sich ja während der Dauer des Vergleichsreizes immerhin kaum sehr viel in seiner Helligkeit ändern dürfte. Diesem Umstande ist es nach meiner Meinung zuzuschreiben, dass D ü rr mit seiner letzten Methode $\mathrm{zu}$ Resultaten gelangt ist.

Die Thesen Dürr's wurden bald, und zwar im gleichen Laboratorium, in dem sie entstanden wares, widerlegt, nämlich durch

1) Nagel's Handb. Bd. 3 [1] S. 228.

E. Pfl tüger, Archiv für. Physiologie. Bd. 123. 
M. Büchner's Untersuchungen über den Anstieg der Helligkeitserregung ${ }^{1}$ ).

$B$ üchner verglich zwei unmittelbar über einander liegende Flächen, indem er die Helligkeit der oberen (des "Normalreizes") durch die Dauer der Exposition, die der unteren (des „Vergleichsreizes") bei konstanter Dauer der Belichtung durch die Intensität des Reizes variierte. Er bestätigte den bereits von Exner aufgestellten Satz, dass die Maximalzeit sowohl bei Hell-, als auch bei Dunkeladaptation mit zunehmender Intensität kleiner werde. Die von ihm bei Dunkeladaptation gefundenen Maximalzeiten betrugen:

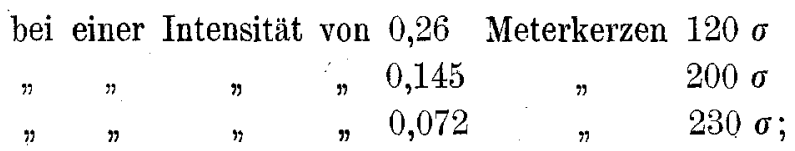

bei Helladaption :

bei einer Intensität von 9 Meterk. $60 \sigma$, bei 57 Meterk. $33 \sigma$.

Noch andere wichtige Ergebnisse förderten Büchner's Versuche zutage, nämlich 1. dass die Helligkeitsempfindung nicht kontinuierlich, sondern diskontinuierlich in Form mehrerer Oszillationen bis zum Maximum ansteigt und ebenso wiederum absinkt; 2. dass die nasale und die temporale Hälfte der Fovea in verschiedener Weise erregbar sind.

Diese beiden Thesen sind für die Untersuchung der Unterschiedsschwelle im ansteigenden Teile einer Helligkeitsempfindung von grösster Wichtigkeit: Aus der ersteren ergibt sich die Wahrscheinlichkeit, dass auch die zeitlichen Unterschiedsschwellen in Form von Oszillationen ansteigen, aus der zweiten, dass jedwede monokulare photometrische Untersuchung von vornherein zweifelhafte Resultate ergibt.

Und damit möchte ich gleich den ersten Punkt meiner Kritik der Büchner'schen Versuchsanordnung begründen, welche ebenso wie alle vorherigen nur für ein Auge eingerichtet war. Sodann möchte ich" bemerken, dass er die Fixation fast ganz ausser acht gelassen hat. Allerdings schrieb $\mathrm{B} u ̈ \mathrm{chn}$ er ${ }^{2}$ ), dass nach einer Dunkeladaptation von etwa 20 Min. „sich herausstellte, dass durch eine nicht vollständige Abdunkelung des Spaltapparates auf dem Beobachtungsfelde ein minimaler Nebel erschien", der ihm die

1) M. Büchner, Über den Anstieg der Helligkeitserregung. Wundt's psychol. Studien, Bd. 2. 1907.

2) l. c. S. 9. 
Fixation erleichterte; aber gerade dadurch hat Büchner gefehlt, denn so ein schwacher Lichtnebel übt nicht auf die Fovea, sondern auf die parafoveale und noch weiter exzentrische Region eine Attraktion aus, wie aus den Untersuchungen über das Dämmerungssehen mit Sicherheit hervorgeht. Da ferner die Vergleichsfelder nie absolut dunkel waren, so ist mit Büchner's Versuchen auch nicht der Anstieg der Helligkeit vom Nullpunkte aus. untersucht worden. Sodann war es ein Fehler, dass die beiden Vergleichsfelder auf der Beinglasplatte ganz ohne scharfe Grenze in einander übergingen. Da ausserdem das Licht durch einen Spalt von einer Breite von $0-2 \mathrm{~mm}$ direkt auf den Schirm fiel, ohne etwa vorher durch Linsen gesammelt worden zu sein, so mussten sich wohl störende Beugungserseheinungen gezeigt haben. Der Grösse und Form des belichteten Netzhautbezirkes scheint Bü chner keine besondere Aufmerksamkeit gewidmet zu haben; denn es findet sich bloss gelegentlich einmal die Angabe ${ }^{1}$ ), dass dieselben anfänglich $2^{1 / 2}{ }^{0}$ eingenommen haben und dann auf die Hälfte verkleinert worden seien, weil die Felder besonders in den äusseren Teilen nicht gleichmässig erschienen (wie übrigens nach der Versuchsanordnung zu erwarten war). Schliesslich muss ich noch bemerken, dass die Adaptation in unzulänglicher Weise berücksichtigt wurde. Bei den Versuchen mit Dunkeladaptation wurde zuerst während $20 \mathrm{Min}$. dunkeladaptiert und sodann in Zwischenpausen von 2-3 Min. nacheinander durchschnittlich 25 Versuche gemacht ${ }^{2}$ ). Ein Blick auf die Piper'sche Kurve der Dunkeladaptation lehrt, wie gewaltig sich die Lichtempfindlichkeit des Auges während eines so langen Aufenthaltes im Dunkeln ändert. Auch die zur Helladaptation verwendete Vorrichtung war nicht geeignet, einen bestimmten Adaptationszustand herzustellen, schon deshalb nicht, weil nicht das ganze Gesichtsfeld vor dem Versuche von gleicher Helligkeit erfüllt war. Ausserdem ist aus Büchner's Versuchsbeschreibung nicht zu entnehmen, wie lange der zur Helladaptation dienende Schirm vor jedem Versuche angeschaut wurde, und welche Zeit zwischen der Betrachtung. dieses Schirmes und dem Erscheinen der Vergleichsreize verging.

Ich vermute, dass sich die ausserordentlich kurzen Maximalzeiten von 33, bezw. $60 \sigma$ Dauer daraus erklären, dass das Auge

1) 1. c. S. 22 .

2) 1. c. $5.9-11$. 
bei den zugehörigen Versuchen noch nicht zur Ruhe gekommen war, und dass daher die genannten Zahlen eigentlich bloss die Maximalzeiten der Helligkeitszuwüchse bezeichnen.

Aus den im vorstehenden angefübrten Untersuchungen ergeben sich ausserordentlich verschiedene Angaben für die Maximalzeiten, nämlich, ihrer Grösse nach geordnet:

1. Charpentier . 0,012-0,062 Sek.,

2. Martius . . 0,013-0,093 Sek.,

3. Kunkel . . 0,0573 (für Rot)-0,18 Sek. (für Blau),

4. Bü cluner. . . 0,12-0,23 Sek.,

5. Exner . . . 0,1188-0,2873 Sek.,

6. Petrèn... grösser als 0,3 Sek.,

7. Dürr . . . 0,269 (für Weiss) und 0,529 Sek. (für

homogene Farben).

Allerdings lassen sich die Angaben mit Ausnahme derjenigen von Dürr, die ja nach des Autors Meinung allgemeine Gültigkeit. haben sollten, schwer mit einander vergleichen, da nur $B$ üchner die untersuchten Lichtintensitäten in photometrischen Einbeiten angab. Wenn man aber auch angesichts dessen nur die oberen Grenzen der gefundenen Werte vergleicht, so ergeben sich dennoeh sehr grosse Differenzen; so würde beispielsweise die Maximalzeit für einen und denselben Lichtreiz nach Dür 22 mal so gross sein wie nach Charpentier.

Da die Kenntnis der Maximalzeit für Untersuchungen über den ansteigenden Teil einer Lichtempfindung selbstverständlich sehr wichtig ist, bielt ich es für nötig, die bisherigen Augaben hierüber einer Kritik zu unterziehen. Dureh diese fühle ich mich zu der Meinung berechtigt, dass die von den Autoren angebenen Zeiten zufolge der nachweisbaren Versuchsmängel keinen Anspruch auf Sicherheit erheben können; vielmehr ergibt sich mit grösster Wahrscheinlichkeit nur das eine, dass die Maximalzeiten tatsächlich von der Intensität des Lichtreizes abhängen. Ob, wie Petrèn postulierte, die Untersuchung der zeitlichen Unterschiedsschwellen zur Bestimmung der Maximalzeit geeignet ist, das sollte sich ebenfalls bei meinen Versuchen zeigen.

\section{Teil. Versuchsanordnung.}

Das Prinzip meiner Versucbe besteht, wie bereits erwähnt, in dem Vergleiche zweier Lichtempfindungen, welche durch möglichst gleiche 
Reize, die zu verschiedenen Zeiten beginnen und gleichzeitig endigen, von zwei symmetrischen Stellen des Auges aus hervorgerufen werden. Für die Versuchsanordnung sind vor allem folgende Bedingungen zu präzisieren:

1. Die Lage der geprüften Netzhautstellen, hauptsächlich, ob dieselben der Fovea oder der Peripherie angehören;

2. deren Grösse und Form;

3. deren Distanz voneinander;

4. die Fixation;

5. der Adaptationszustand des Auges;

6. ob die Untersuchung monokular oder binokular vorgenommen wird;

7. die Beschaffenheit der Reizflächen;

8. die Bestimmung der Reizdauer;

9. die Reizpause;

10. der Zustand des Beobachters.

Ad 1. Eine streng durchgeführte Trennung der Untersuchung der Fovea und der Peripherie bezüglich der Unterschiedsschwelle schien mir für die Deutung der Versuchsergebnisse schon anbetrachts des sonst so verschiedenen Verhaltens dieser beiden Gebiete von Anfang an unerlässlich. Eine scharfe Trennung in dieser Beziehung ist bisher nur von Petrèn durchgeführt worden, indem dieser seine Untersuchungen auf die Fovea beschränkte. Dass das Ansteigen der Netzhauterregungen in der Fovea und Peripherie ein ganz verschiedenes ist, lehrt schon folgender einfacher Versuch: Ich exponierte einen Kreis, welcher etwa den doppelten Durchmesser der Fovea hatte, wäbrend einer untermaximalen Zeit; es zeigte sich hierbei der Rand viel heller als die Mitte; in der Mitte erschien ein dunklerer Rhombus mit horizontaler längerer Diagonale. Ich bezog diese hübsche subjektive Gesichtserscheinung auf die Fovea und wiederholte den gleichen Versuch mit einem sicher in das Gebiet derselben fallenden Reizfelde. Wie nach mejner Annahme zu erwarten war, blitzte dasselbe homogen auf ${ }^{1}$ ).

1) Das Ergebnis dieses Versuches hat in der jüngsten Zeit B. Berliner (Der Anstieg der reinen Farbenerregung im Sehorgan. Wundt's psycbol. Studien Bd. 3 S. 131. 1907), olne den Versuch selbst anzustellen, theoretisch postuliert. Er schreibt a. a. 0.: „Am leichtesten spricht offenbar derjenige Teil der Netzhaut_an, der die Zentralgrube ringförmig und ziemlich scharf umgibt. - 
Auch die bisher bekannten Erscheinungen der Trägheit der Fovea weisen darauf hin, dass eine Trennung der beiden Gebiete unerlässlich ist. Die im folgenden publizierten Untersuchungen habe ich nur mit fovealen Reizen angestellt.

Ad 2. Aus diesem Grunde mussten die zu vergleichenden Reize in ibrer Form und Grösse der Fovea angepasst sein. Ich gab denselben deshalb die Gestalt zweier gleicher Halbkreise, welche mit ihrem vertikal gerichteten Durchmesser im Fixationspunkte zusammenstiessen. Da ibre Bilder sicher in den Bereich der Fovea fallen sollen, muss sich ihre Grösse nach ihrer Entfernung vom beobachtenden Auge richten. Diese beträgt bei meinen Versuchen etwa $38 \mathrm{~cm}$. Ich habe eine so grosse Entfernung gewählt, um weniger akkommodieren zu müssen. In diese Entfernung vom Auge projiziert entspricht der Fovea ein Durchmesser von etwa $1 \mathrm{~cm}$. Wegen der unvermeidlichen geringen Blickschwankungen gab ich den beiden Reizfeldern, um deren Bilder mit grösserer Sicherheit nur in das foveale Gebiet zu entwerfen, eine Grösse von nur $8 \mathrm{~mm}$ Durchmesser. Das Netzhautbild hatte also einen Durchmesser von etwa 72 Minuten. - Dies entspricht auch Nage l's Ermittlungen ${ }^{1}$ ), nach welchen die Ausdehnung des zentralen Netzhautbezirkes, inverhalb dessen die Erscheinungen des Dämmerungssehens nicht wahrgenommen werden, etwa $1,5^{\circ}$ im Durchmesser beträgt.

Ad 3. In zahlreichen Vorversuchen konnte ich die bekannte Tatsache bestätigen, dass die Vergleichung zweier Lichtreize um so schwieriger und unsicherer ist, je weiter sie von einander entfernt sind. Andererseits ist gegen die Vergleichung eng benachbarter Lichtreize von Dürr der Einfluss der Irradiation geltend gemacht worden. Ob zwischen der grösseren subjektiven Helligkeit des länger dauernden Reizes und der, geringeren des kürzeren Reizes bei unmittelbarer Nachbarschaft Induktionswirkungen eintreten, lässt sich vorderhand nicht feststellen; wahrseheinlich ist dies um so weniger zu erwarten, je geringer die Differenz der Expositionsdauer ist. Hingegen erwächst aus der unmittelbaren Nachbarschaft eine grosse Schwierigkeit für die anfängliche subjektive Gleichstellung der beiden Reize,

Würde man ein grösseres Feld vollkommen momentan eine entsprechende Zeit exponieren, würde man wahrscheinlich einen Ring oder wenigstens einen ausgesparten Fleck erblicken, welcher der eigenen Fovea entspricht."

1) Nagel's Handb. d. Physiol. Bd. 3 [1] S. 182. 
indem ein anfangs sehr deutlicher Helligkeitsunterschied zwischen denselben bei ruhiger Fixation bald verschwindet, so dass sie völlig gleich erscheinen. Diese von Hering als "lokale Adaptation" beschriebene Erscheinung geht bei geringen Helligkeitsdifferenzen sehr rasch vor sich und bildet die Hauptschwierigkeit der Gleichstellung der beiden Reizfelder in ihrer Helligkeit, die ja allen Versuchen vorhergehen muss. Darauf komme ich später noch zurück. Das eine hat sich aus meinen Vorversuchen sicher ergeben, dass weder ich, noch meine Versuchspersonen imstande waren, durch Differenzen der Expositionsdauern bewirkte Helligkeitsunterschiede zwischen distanten Reizfeldern wahrzunehmen, welche bei Annäherung derselben gegen einander fast bis zur Berührung sehr deutlich wurden. Aus diesem Grunde halte ich die Vergleichung zweier distanter Reizfelder. überhaupt für die Bestimmung der Unterschiedsschwelle für unbrauchbar und habe die beiden zu vergleichenden Halbkreise einander bis auf einen vertikalen schwarzen Trennungsstrich genähert.

Ad 4. Wenn es sich um das Studium der Wirkung eines Lichtreizes von bestimmter Dauer auf eine bestimmte Netzhautstelle handelt, so ist es eigentlich selbstverständlich, dass dieser Lichtreiz während der ganzen Zeit seines Bestandes auf diese eine Netzhautstelle wirken muss, und dass er nicht auch zeitweilig auf andere Netzhautstellen fallen darf. Diese Versuchsbedingung ist um so wichtiger, je kleiner die untersuchte Netzhautstelle ist. Ihr wird nur durch eine möglichst sichere Fixation Genüge geleistet. Da eine solche in den Untersuchungen von einigen der zitierten Autoren ausser acht gelassen worden ist, glaube ich, diese Grundbedingung für eine richtige Deutung der Versuchsergebnisse besonders hervorheben zu müssen, sowie dies auch Dürr und Wirth (in seinem erwähnten Referate) getan haben. Besonders wenn die zu vergleichenden Lichtreize auf eng benachbarte Netzhautstellen treffen, ist die Isolierung derselben sehr erschwert, da geringe Blickschwankungen wohl nicht auszuschliessen sind. Diese treten um so eher auf, je länger das Auge mit der starren Fixation angestrengt wird. Ich habe deshalb durch akustisehe Signale den Beobachtern Kenntnis über das Herannahen des Lichtreizes verschafft, so dass sie imstande waren, erst 1-2 Sek. vor demselben die Fixationsmarke ins Auge zu fassen. Zur Fixation verwendete ich anfangs vier kleine, mit de-Haen'scher Leuchtfarbe bestrichene Quadrate von etwa $1^{1 / 2} \mathrm{~mm}$ Seitenlängen. Ich brachte dieselben so rings um die Reiz- 
fläche an, dass sie die Ecken eines mit der grösseren Diagonale horizontal liegenden Rhombus bildeten, in dessen Mitte das Reizfeld lag. Die Distanz der beiden seitlichen Leuchtmarken von letzterem betrug genau $10^{\circ}$, die der beiden oberen etwa $7^{\circ}$. Nach verschiedenen Vorversuchen babe ich diese Anordnung der Leuchtmarken als die günstigste gefunden. Die grosse Distanz der Marken vom Lichtfelde wählte ich deshalb, weil sie so den zu untersuchenden Bezirk weniger beeinflussten, und weil die Empfindlichkeit der Peripherie im dunkeladaptierten Auge bei einer Distanz von 10-20 vom Zentrum an grössten ist. Der bläulich-violette Schimmer dieser Leuchtfarbe liess sie als ganz besonders zweekdienlich erscheinen, da ja das Maximum der Dämmerungswerte im kurzwelligen Ende des Spektrums, etwa bei $529 \mu \mu$, liegt ${ }^{1}$ ). Diese Leuchtmarken erwiesen sich aber naturgemäss nur bei den wenigen Vorversuchen verwendbar, die ich bei Dunkeladaptation vornahm. Für die Helladaptation musste ich eine andere Fixationsmarke verwenden. Als solche diente mir eine etwa $4 \mathrm{~mm}$ lange, tiefrote vertikale Linie entlang der schwarzen Trennungslinie der beiden Reizfelder, welche von einem sehr dünnen glühenden Platiudraht gebildet wurde. Dieser war in einem von einem Akkumulator gespeisten Stromkreise eingeschaltet und konnte durch Verwendung eines Widerstandes in verschiedener Intensität leuchtend gemacht werden. Ich verwendete für meine eigenen Versuche eine an der Schwelle stehende Helligkeit, bei welcher der Platindraht tief dunkelrot erschien und nur foveal deutlich gesehen wurde. Nagel und Schäferiª) erwähnen, dass es sehr sehwer sei, eine solche Reizmarke beim Hineinblicken in den dunkeln Apparat aufzufinden. Ich habe dies im Anfange auch bei mir selbst bemerkt, später aber konnte ich die Marke sofort auffinden, da ich schon darin geübt war, dem Blicke gleich die gewünschte Richtung zu geben. Ungeübte Beobachter waren überhaupt nicht imstande, die Marke aufzufinden, und selbst für meine geübten Mitarbeiter musste der Widerstand etwas verringert und die Marke auf diese Art zuerst etwas heller gemacht werden. Es wurde übrigens der Stromkreis immer kurz vor dem Herannahen des

1) Nagel's Handb. d. Physiol. Bd. 3 [1] S. 174.

2) W. A. Nagel und K. L. Schäfer, Über das Verhalten der Netzhautzapfen bei Dunkeladaptation des Auges. Zeitschr. f. Psychol. u. Physiol. d. Sinnesorgane Bd. 34. 1904. 
Lichtreizes anf ein Glockenzeichen hin geschlossen, und darauf glühte der Draht im ersten Momente immer bedentend heller, so dass es auch leichter war, ihn in diesem Stadium aufzufinden. Zufolge ihrer geringen Helligkeit warf diese Marke keinen wahrnehmbaren roten Schein auf die Umgebung.

Dass eine solche im Zentrum des Reizfeldes angebrachte Fixationsmarke die Schwellenwerte nicht merklich heeinflusst, haben Nagel und Schäfer ${ }^{1}$ ) gezeigt. Sofort nach dem Verschwinden des Lichtreizes hatte der Beobachter den Blick von der Marke abzuwenden, oder er konnte auch den sie versorgenden Stromkreis durch einen ihm zur Hand stehenden Schlüssel öffnen.

Ad 5. Die Versuche der vorliegenden Arbeit sind bei Helladaptation angestellt. Es handelte sich darum, ein bestimmtes Stadium derselben für das ganze somatische Gesichtsfeld herzustellen. Ich habe mir einen sehr einfachen Apparat für diesen Zweck aus einer Lampenkugel aus Beinglas hergestellt, indem ich diese in der Richtung eines Meridians teilte und die scharfen Ränder des Glases einsäumte. Diese "Adaptationsbrille" passte sich ausgezeichnet an Kopf und Gesicht an; der für den Lampenzylinder bestimmte Ausschnitt kam der Nase zugute. Durch diesen Schirm blickte der Beobachter gegen die etwa $1 \frac{1}{2} \mathrm{~m}$ entfernte Lichtquelle. Das Licht wurde durch das Beinglas in möglichst gleichmässiger Weise zerstreut, so dass tatsächlich das ganze Gesichtsfeld homogen beleuchtet erschien, und zwar, da die Lichtquelle ein ebenfalls durch eine Beinglaskugel gedämpfter Auerbrenner bildete, in einer Helligkeit, welche bedeutend geringer war als die des bewölkten Himmels am Tage, so dass man beim Durchblicken gar kein Blendungsgefühl verspürte. Der Hauptwert dieser Adaptationsbrille besteht darin, dass auch die ganze Peripherie gleichmässig erhellt ist, da sich der Schirm über die Schläfen legt. Die Nachbilder, welche man beim Beginne der Versuche stets noch mit sich trug, verschwanden nach etwa 5 Sek. wäbrend der Beleuchtung durch den beschriebenen Schirm. Da die Versuche im Dunklen meistens nur $1 / 2-1$ Min. dauerten, so war eine Störung der Helladaptation dadureh nur in einem Grade. zu erwarten, welchen man wohl vernachlässigen kann, da ja nach Piper's Untersuchungen ${ }^{2}$ ) der Einfluss der Dunkeladaptation in den ersten

1) l. c.

2) H. Piper, Über Dunkeladaptation. Zeitschr. f. Psychol. u. Physiol. d. Sinnesorgane Bd. 31. 1903. 
Minuten kaum merkbar ist. Da die Pause zwischen den einzelnen Versuchen etwa 1 Min. betrug, während welcher Zeit der Beobachter durch die Adaptationsbrille blickte, so wurde ein eventueller Einfluss des kurzen Aufenthaltes im Dunkeln dadurch sicher wieder aus. geglichen und ein konstanter Zustand der Helladaptation hergestellt; nach Lohmann's Ermittlungen ${ }^{1}$ ) steigt ja die Helladaptation gerade in der ersten Minute sehr rapid an. Da das ganze Gesichtsfeld gleichmässig belichtet war, stellten sich auch keine Nachbilder ein.

Auf die Notwendigkeit einer möglichst konstanten, gleichmässigen Belichtung des ganzen Sehfeldes zur Herstellung einer bestimmten Helladaptation hat schon Petrèn ${ }^{2}$ ) hingewiesen und diese Bedingung auch durch seine Versuchsanordnumg nahezu erfüllt. Es wurden trotzdem in späteren Arbeiten unzulängliche Methoden hiefür angewendet. So bat Schaternik of $f^{3}$ ) „durch Hinạsschauen gegen den hellen Himmel während einiger Minuten helladaptiert", Dürr ${ }^{4}$ ), Nagel und Schäfer ${ }^{5}$ ), Révész ${ }^{6}$ ), Lohmann ${ }^{7}$ ) und

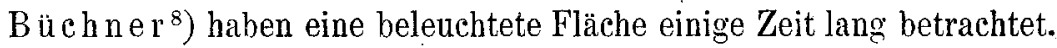
Bei Dürr's Versuchen war diese Fläche wenigstens in allen ibren Teilen dadurch konstant beleuchtet, dass sie ihr Licht von einem breiten Fenster aus erhielt und photometrisch kontrolliert wurde, wäbrend die Fläche bei $\mathrm{Nagel}$ und Lohmann nur von einer Lampe aus beleuchtet wurde, wodurch auf der Fläche selbst Helligkeitsdifferenzen erscheinen mussten. - Lohmann sagt auch ausdrücklich, dass er mit Rücksicht auf die nach dem Anblicken der hellen Flächen eingetretenen Nachbilder bis zur Schwellenbestimmung 10 Sek. habe warten müssen, obwohl es „das Ideal der Bestimmung gewesen wäre, wenn sofort und unmittelbar nach Ablauf der Zeit,

1) W. Lohmann, Über Helladaptation. Zeitschr. f. Psychol. u. Physiol. d. Sinnesorgane Bd. 41. 1906.

2) l. c. S. 425 .

3) M. Schaternikoff, Einfluss der Adaptation auf die Erscheinung des Flimmerns. Zeitschr. f. Psychol. u. Physiol. d. Sinn. Bd. 29 S: 251.1902.

4) 1. c.

5) $1 . \mathrm{c}$.

6) G. Révész, Über die Abhängigkeit der Farbenschwellen von der achromatischen Erregung. Zeitschr. f. Psychol. u. Physiol. d. Sinnes re Bd. 41. 1906.

7) $1 . c$.

8) 1. c. 
in welcher exponiert wurde, ein Schwellenwert bestimmt worden wäre". Ein noch grösserer Fehler, war es, wie mir scheint, wenn Révész einen möglichst grossen Teil der Netzhaut helladaptierte, indem er den Blick über eine solche Fläche wandern liess, wobei ja ein fortwährender Wechsel in der Beleuchtung eintrat. Vor kurzem hat nun S. Garten ${ }^{1}$ ) einen Apparat zur gleichmässigen Beleuchtung des ganzen Gesichtsfeldes konstruiert, welcher aus mehreren mit Hilfe von Holzgestellen konzentrisch aufgestellten Bogen von Lichtpauspapier von $90 \mathrm{~cm}$ Höhe besteht, in deren Zentrum sich das beobachtende Auge befindet. Diese Bogen werden von vorneher durch ein Fenster des Zimmers mit Tageslicht beleuchtet. Leichter herzustellen und doch auch bequemer und handlicher scheint mir ein Beinglasschirm von der oben angegebenen Art.

Ad 6. Meine Beobachtungen sind alle binokular vorgenommen worden. Diese Untersuchungsweise ist nicht nur angenehmer und weniger ermüdend als die monokulare, sondern von dieser nach meiner Meinung bei der Untersuchung der Unterschiedsempfindlichkeit im Prinzipe verschieden. Es scheint auffällig, dass alle Autoren, welche ich eingangs anführte, nur monokulare Untersuchungen angestellt haben; vermutlich waren daran hauptsächlich ihre Versuchsanordnungen schuld, welche nur monokulare Beobachtung zuliessen. Es hat nun allerdings Révés z ${ }^{2}$ ) gefunden, dass die Lichtempfindlichkeit eines Auges, an Schwellenwerten gemessen, durch gleichzeitige Lichtreizung des anderen Auges nicht verändert wird, und $\mathrm{Piper}{ }^{3}$ ) hat beobachtet, dass für helladaptierte Angen bei Gleichheit der monokular und binokular beobachteten Lichtintensität auch Gleichheit der Helligkeitsempindung eintritt. Er fand hingegen, dass bei Dunkeladaptation bei binokularer Fixation der Helligkeitseindruck grösser sei als bei monokularer. Demgegenüber gab Wölfflin ${ }^{4}$ )

1) S. Garten, Über die Wahrnehmung von Intensitätsveränderungen bei möglichst gleichmässiger Beleuchtung des ganzen Gesichtsfeldes. Pflüger's Arch. Bd. 118 S. 283.1907.

2) G. Révész, Wird die Lichtempfindlichkeit eines Auges durch gleichzeitige Lichtreizung des anderen Auges verändert? Zeitschr. f. Psychol. u. Physiol. d. Sinnesorgane Bd. 39 S. 314. 1905.

3) H. Piper, Über das Helligkeitsverhältnis monokular und bixokular ausgelöster Lichtempfindungen. Zeitschr. f. Psychol. u. Physiol. d. Sinn. Bd. 32 S. 161.1908.

4) E. Wölfflin, Der Einfluss des Lebensalters auf den Lichtsinn bei dunkeladaptiertem Auge. Arch. f. Ophthalm. Bd. 61. 1905. 
an, dass er auch bei Dunkeladaptation die Helligkeitsempfindung bei binokularer und monokularer Betrachtung gleich gefunden habe. Gerade an Schwellenwerten ausgeführte Untersuchungen lassen hingegen den grossen Unterschied zwischen binokularer und monokularer Untersuchungsweise unleugbar erkennen. Zuerst bat $\operatorname{Sim} \mathrm{n}^{\mathbf{1}}$ ) dies besonders hervorgehoben. Bei seinen Versuchen zeigte sich die Unterschiedsempfindlichkeit für Helligkeitsdifferenzen bei binokularer Betrachtung stets bedeutend grösser als bei monokularer. Sodann fand Piper ${ }^{2}$ ), dass die durch Dunkeladaptation hervorgerufene Empfindlichkeitssteigerung binokular doppelt so gross ist wie monokular. Sherrington ${ }^{3}$ ), schloss sogar aus seinen Beobachtungen, dass das Talbot'sche Gesetz wohl für das Sehen mit einem Auge, nicht aber für das Sehen mit beiden Augen Gültigkeit habe. Zuletzt hat $\mathrm{Garte} \mathrm{n}^{4}$ ) berichtet, dass die Unterschiedsempfindlichkeit für Intensitätsveränderungen einer das ganze Gesichtsfeld erfüllenden Beleuchtung bei monokularer Beleuchtung nur die Hälfte des bei binokularer Betrachtung gefundenen Wertes betrage. Das wichtigste Argument gegen die monokulare Untersuchung des Verlaufes einer Lichtempfindung scheint mir die von $B$ üchners) gefundene Verschiedenheit der Reaktion der nasalen und temporalen Foveahälfte zu bilden.

Ad. 7. Die beiden mit einander zu vergleichenden Reizflächen müssen untereinander und in allen ihren Teilen möglichst gleichartig, das sie bestrahlende Licht möglichst konstant, die Helligkeit möglichst variierbar sein; ich habe mich davon überzeugt, dass bei durchfallendem Lichte weder Mattscheiben, noch Transparentpapier genau homogene Reizflächen darzubieten vermögen. Recht gut können solche mit Hilfe von Beinglas erzeugt werden ${ }^{6}$ ). Dieses soll möglichst dünn, genau planparallel zugeschliffen und unbedingt

1) R. Simon, Über die Wahrnehmung von Helligkeitsunterschieden. Zeitschr. f. Psychol. u. Physiol. d. Sinnesorgane Bd. 21 S. 439. 1899.

2) Piper, Über Durkeladaptation. L. c.

3) C. S. Sherrington, Observations on "Flicker" in binocular vision. Proc. Roy. Soc. vol. 71 p. 468.1902.

4) $\mathrm{l}$. $\mathrm{c}$.

5) 1. c.

6) Am geeignetsten für derartige Lichtfl̈̈chen dürften die Foucault' schen. Schirme sein, d. i. zwei Glasplatten, zwischen denen eine gleichartige Schicht von Stärkemehl eingeschlossen ist. 
schlierenfrei sein. Dies fällt bei der Kleinheit der für foveale Reize verwendeten Flächen besonders ins Gewicht. Um solche Stücke von Beinglas zu erhalten, habe ich mir entweder aus einer grossen Beinglastafel ein möglichst reines Stück ausgesucht und ausschneiden oder, wenn ein reines Stück nicht $z u$ finden war, ein dickeres Beinglas durch Abschleifen von Schlieren befreien lassen. In letzterem Falle zeigten die Beinglasflächen einen Stich ins Rötliche, welcher von mechanisch nicht entfernbaren Spuren des zum Polieren verwendeten "Rouge" herrührte. Durch mehrstündiges Einlegen in verdünnte Salzsäure wurde diese Verunreinigung entfernt.

Über die Schwierigkeit, welche die Vergleichung der beiden Reizflächen zum Zwecke der anfänglichen Gleichstellung der objektiven Helligkeiten bereitete, habe ich mich bereits früher geäussert. Die Gleichstellung wurde in der Weise vorgenommen, dass die beiden Reize nicht nur während beliebiger konstanter Dauer, sondern während ganz bestimmter untermaximaler Zeiten mit einander verglichen wurden; schienen sie sodann gleich, so wurde der Vergleich der beiden Reizflächen mit sicher an der Schwelle stehender Differenz der Expositionsdauer wiederholt und einmal der rechte, einmal der linke Reiz um dieselbe Differenz grösser gemacht. Waren die Reize tatsächlich objektiv gleich, so musste auch im letzteren Falle die Helligkeit an der Stelle mit der grösseren Reizdauer gerade noch als grösser empfunden werden. Durch zahlreiche derartige Kontrollversuche, welche sowohl von mir, als auch von den Versuchspersonen ausgeführt wurden, wurde eine möglichst genaue Gleichheit der beiden Reizflächen ermittelt. Veränderungen des Helligkeitsverhältnisses der beiden Reizflächen um sehr geringe Beträge konnten durch Drehung eines Kalkspat-Prismas ${ }^{1}$ ) bewirkt werden.

Ad. 8. Die genaue Bestimmung der Reizdauer erfolgte durch Verstellen der Sektoren einer Scheibe, welche vor einem Spalte rotierte. Durch diesen Spalt war wie bei Martius' Apparat bewirkt, dass der Lichtreiz in allen Teilen des Reizfeldes gleichzeitig auftauchte, bzw. verschwand. Die Geschwindigkeit der Scheibe konnte durch einen Helmholtz'schen Rotationsapparat sehr genau reguliert werden. Die Gleichmässigkeit der Umdrehungen prüfte ich zu Beginn der Untersuchung mittelst eines an der Achse der Scheibe angebrachten Schleifkontaktes und eines Markiermagneten, der, auf

1) Vgl. S. 195. 
der Eisenbahn des Marey'schen Myographions angebracht, die einzelnen Umdrehungen auf der Trommel des Marey'schen Kymographions fortlaufend markierte. Die Distanzen zwischen je zwei beliebigen Zacken wurden mit dem Zirkel vielfach gemessen, und es ergaben sich fast niemals merkliche Verschiedenheiten. Im Verlaufe der Versuche nahm ich die Zählung der Umdrehungen der Scheibe derart vor, dass ich an derselben einen doppelt zusammengelegten Papierstreifen, der von einer Klemme gehalten war, schleifen liess: sobald der Ausschnitt der Scheibe daran vorbeikam, entstand durch !das Einschlagen des Papierstreifens ein deutliches Geräusch. Die Zahl dieser Geräusche wurde während einiger Minuten mit Hilfe einer gutgehenden Taschenuhr gezählt. Auch diese Zählungen ergaben einen Beweis für die grosse Konstanz der Umdrehungsgeschwindigkeit.

Ad. 9. Die Reizpause währte in meinen Versuchen so lange, bis der Experimentator eine neue Einstellung der Scheibensektoren vorgenommen hatte, durchschnittlich eine halbe bis eine Minute. Eine genauere Bestimmung der Reizpause schien mir, solange die Versuche bei Helladaptation vorgenommen wurden, aus den früher angeführten Gründen nicht nötig.

Ad. 10. Die Versuchsresultate dieser wie jeder anderen subjektiven Untersuchung sind natürlich in hohem Maasse von der Aufmerksamkeit, Stimmung, Übung und individuellen Veranlagung des Beobachters abhängig.

Mit Rücksicht auf die Ungestörtheit der Aufmerksamkeit hat Mc. Dougall ${ }^{1}$ ) für Versuche mit kurzdauerndem Lichtreize die Forderung aufgestellt, dass während des Lichtreizes jeder andere sinnliche Reiz fehle, sei er optisch oder akustisch. Die Aufmerksamkeit des Beobachters darf weder durch Gespräche oder sonstwie während der Versuche abgelenkt werden, noch erlahmen. Die letztere Gefahr ist aber noch grösser als die erstere. Ich habe deshalb mit Hilfe einer Baltzar'schen Stromunterbrechungsuhr, die mit einer elektrischen Klingel in Verbindung war, alle drei oder fünf Sekunden ein Glockenzeichen geben lassen, so dass der Beobachter dadurch vom Herannahen des in den meisten Fällen alle 6-18 Sekunden wiederkebrenden Lichtreizes Kenntnis erhielt und

1) Mc. Dougall, The sensations excited by a singte momentary stimulation of the eye. Journ. of Psychol. vol. 1. 1904. 
die Fixationsmarke ins Auge fassen konnte. Es wurden jedesmal vier Beobachtungen hintereinander ausgeführt und dann wieder eine Pause eingeschaltet. Petrèn ${ }^{1}$ ) glaubt, dass der Grad der Aufmerksamkeit für derartige Versuche durch Übung erhöht werden könne. Jedenfalls hängt sowohl die Aufmerksamkeit als auch die Unterschiedsempfindlichkeit in hohem Maasse von der Stimmung des Beobachters ab. Dieses habe ich gerade während der schönen Frühjahrs- und Sommernachmittage an meinen Mitbeobachtern bemerkt, die der Aufenthalt in dem nur von einem Auerbrenner erleuchteten und während der Versuche selbst völlig abgedunkelten Zimmer bei der grossen Hitze, welche durch den Blechkasten mit der Lichtquelle noch gesteigert wurde, oftmals misslaunisch machte. Es kam dann hier und da zu gänzlicher Unbrauchbarkeit der Versuchsresultate, so dass die Versuche abgebrochen werden mussten. Bei meinen eigenen Experimenten zeigte sich mehrmals recht deutlich der Einfluss von Affekten in einer grossen Unsicherheit des Urteiles über das Helligkeitsverhältnis der dargebotenen Reize. In solchen Fällen mussten die Beobachtungen unbedingt auf etwa eine halbe Stunde unterbrochen werden. Ganz auffallend war eine Steigerung der Unterschiedsempfindlichkeit bei gehobener heiterer Stimmung des Beobachters. Nervöse Reizbarkeit durch Überanstrengung oder nach durehwachten Nächten hatte manchmal deutliche Verminderung der Unterschiedsschwelle zur Folge. Im gleichen Sinne erwähnen auch Johansson und Petrèn ${ }^{2}$ ), dass einer ihrer Mitbeobachter, der sonst ein sehr regelmässiges Leben führte, bei Versuchen, welche er nach einer durchschwelgten Nacht vornahm, eine merklich erhöhte Unterschiedsempfindlichkeit zeigte.

Den grössten Einfluss auf die Versuchsresultate unter den subjektiven Momenten hat aber die Übung. Diese Tatsache kam bei unseren Versuchen in überaus auffälliger Weise zur Geltung. Sehon Simon ${ }^{3}$ ) hat auf den grossen Einfluss der Übung hingewiesen und angegeben, dass er denselben auch nach monatelangen Untersuchungen an sich selbst als in beständiger Zunahme begriffen wahrgenommen habe. Auch Petrèn ist bei seinen langdauernden

1) Petrèn, Untersuchungen über den Lichtsinn. L. c. S. 439.

2) S. V. Johansson und H. Petrèn, Untersuchungen über das Weber'sche Gesetz beim Lichtsinn des Netzhautzentrums. Skand. Arch. Bd. 15 S. 35.1904. 3) $1 . \mathrm{c.}$ 
Untersuchungen sehr bald auf den Einfluss der Übungen aufmerksam geworden. Um eine wirklich richtige Kurve für den Verlauf der Unterschiedsempfindlichkeit zu erhalten, müsste man eigentlich nur solche Versuchsresultate verwenden, welche im Verlaufe eines Tages gewonnen sind̉. Da man aber mit Rücksicht auf die Ermüdung und die grosse Zahl der zur Fixierung nur eines Punktes der Kurve nötigen Versuche immer eine lange Zeit braucht, um die ganze Kurve zusammensetzen zu können, so kann dieser überhaupt nur eine relative Gültigkeit zugesprochen werden; darüber muss man sich von Anfang an klar sein. Schliesslich ist der Verlauf einer solchen Kurve für fast jeden einzelnen Beobachter mehr oder

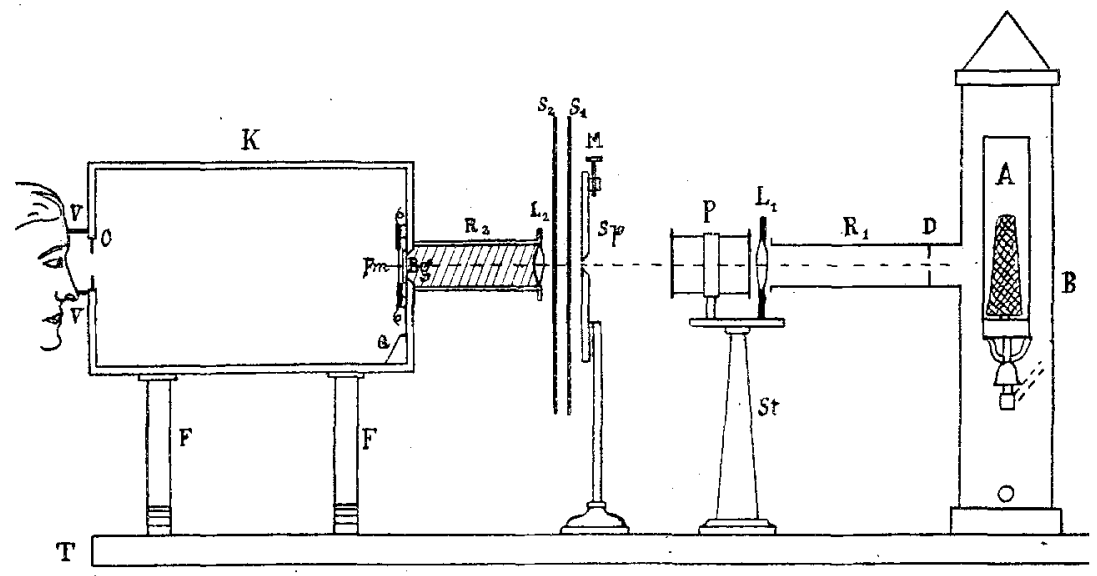

Fig. 1.

weniger verschierlen, da die individuelle Befähigung für subjektive Untersuchungen sich innerhalb sehr weiter Grenzen bewegt. Ich will schliesslich noch bemerken, dass ich eine Schädigung der Augen trotz nahezu täglich mehrstündiger Versuche bei mir nicht bemerkt habe. -

Ich lasse nun die Beschreibung meiner Versuchsanordnung folgen. (Schematische Fig. 1.)

Als Lichtquelle diente ein in seiner Stellung fixierter A uerBrenner $(A)$, welcher infolge längerer Benutzungszeit von Anfang an eine möglichst konstante Leuchtkraft besass, mit einem Mattglaszylinder. Er ist in einem aussen geschwärzten Blechzylinder $(B)$ eingeschlossen, der stabil am Experimentiertische befestigt war und durch mehrere Öffnungen der Luft genügenden Zutritt gewährte. 
Diese Luftlöcher sind zur Verhinderung des Austrittes von Licht maskiert. In der Höhe des mittleren Teiles des Auerstrumpfes ist an diesem Zylinder eine Blechröhre $\left(R_{1}\right)$ von $5 \mathrm{~cm}$ Durchmesser und $20 \mathrm{~cm}$ Länge angesetzt, welche aussen und innen geschwärzt ist. In einer Distanz von etwa $8 \mathrm{~cm}$ vom Mattglaszylinder des Brenners ist in dieser Röhre eine Blende aus schwarzem Blech mit einem quadratischen Ausschnitte von $9 \mathrm{~mm}$ Seitenlänge eingesetzt $(D)$. Die Seiten dieses Ausschnittes stehen genau vertikal und horizontal. Vor der äusseren Öffnung des Ansatzrohres befindet sich eine Konvexlinse von etwa $+12 \mathrm{D}\left(L_{1}\right)$, und, unmittelbar auf diese folgend (in der Richtung des Strahlenganges), ein Kalkspatprisma $(P)$ von etwa $6 \mathrm{~cm}$ Öffnung und $7 \mathrm{~cm}$ Länge in einer Fassung.

Dieses und die Konvexlinse sind von einem besonderen Stativ getragen, welches am Tische angeschraubt ist. Dieses Kalkspat. prisma mit der Linse entwirft von dem quadratischen Ausschnitte des Diaphragmas im Ansatzrohre in einer Distanz von $12^{1 / 2} \mathrm{~cm}$ von der vorderen Fläche des Prismas neben einander zwei ziemlich scharfe Bilder von etwa $12 \mathrm{~mm}$ Seitenlänge, welche von einander durch einen $6 \mathrm{~mm}$ breiten dunkeln Streifen getrennt sind. Das linke Bild des extraordinären Strahlenbündels erschien etwas heller als das rechte (des ordinären Strahlenbündels); liess man durch Drehen des Prismas das erstere etwas emporsteigen, so verlor es ein wenig an Helligkeit. So wenig durchsichtig der Grund hiefür ist, so gut konnte ich diese Eigentümlichkeit zur Gleichstellung der Helligkeit der beiden Reizflächen verwenden ${ }^{1}$ ). Aus den beiden erwähnten quadratischen Bildern wird durch eine Spaltvorrichtung $(S p)$ eine horizontale Linie ausgeschnitten. Diese Spaltvorrichtung besteht aus zwei s'Gravesand'schen Schneiden, deren Distanz von einander durch eine Mikxometerschraube $(\boldsymbol{M} I)$ beliebig geändert werden kann. Die Veränderung der Spaltbreite diente zur genauen Abstufung der absoluten Helligkeit der beiden Reizflächen. Knapp vor dem Spalt rotiert eine Scheibe $(S)$ von $32 \mathrm{~cm}$ Durchmesser, durch deren Ausschnitte die Dauer des Lichtreizes bestimmt wird.

Diese Scheibe besteht aus drei Teilen (Fig. 2), nämlich 1. einer Scheibe aus möglichst steifem schwarzen Pressspahn von der beigefügten Gestalt eines Sektors $(I)$ mit hakenförmigem Fortsatze: $A O$ ist gleich $16 \mathrm{~cm}, O L$ gleich $12^{1 / 2} \mathrm{~cm}$.

1) Vgl. oben S. 191.

E. Pflüger, Arehiv für Physiologie. Bd. 123. 
An der Vorderseite der Scheibe $I$ ist eine Gradeinteilung mit halben Graden aufgeklebt; der Nullpunkt der Einteilung fällt mit dem Ende des hakenförmigen Fortsatzes zusammen. Dieser hat eine Bogengrösse von $50^{\circ}$ (Winkel $A O B=50^{\circ}$ ). - Der ausgeschnittene Sektor hat eine Grösse von $170^{\circ}$ (oberer Winkel $A O C=170^{\circ}$ ). Dahinter befindet sich die Scheibe $I I$ aus dünnerem schwarzem Karton. Diese besteht aus einem Sektor von $100^{\circ}$ (arc. $D E=100^{\circ}$ ); $D O=12,7 \mathrm{~cm}$. Scheibe $I I I$ besteht abermals aus dünnem schwarzen
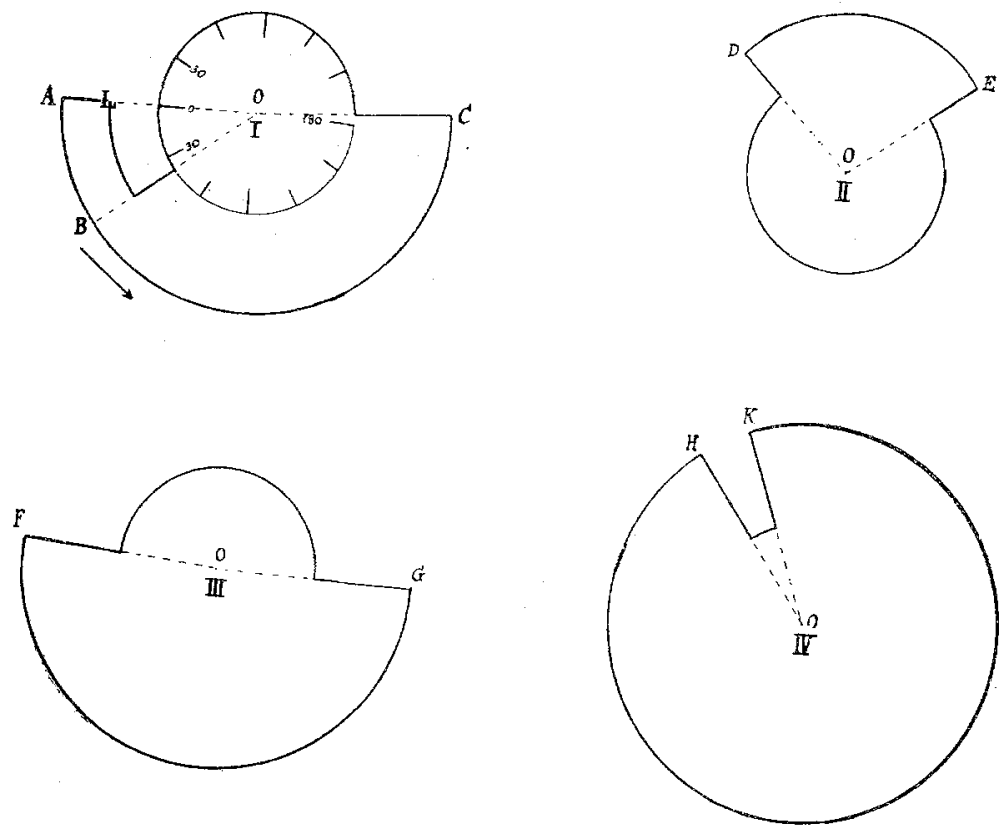

Fig. 2.

Karton und liegt zuhinterst von den drei Scheiben. Winkel $F O G=170^{\circ}$. Diese drei Scheiben werden durch zwei Sterne aus geschwärztem Zinkblech zusammengepresst; der bintere Stern ist an der Achse aufgeschraubt, der vordere wird bloss auf die Achse aufgesteckt und durch eine Schraube an die Scheiben angepresst. Wird diese Schraube etwas gelockert, so können die Scheiben leicht gegen einander versehoben werden. $1 \mathrm{~cm}$ davor befindet sich eine besondere vierte Scheibe $\left(S_{2}\right.$ Fig. $1 ; I V$, Fig. 2), welche sich um die gleiche Achse dreht, aber mit einer durch Zahnradübertragung bewirkten 25 mal geringeren Geschwindigkeit. - Der Sektor $H O K$ beträgt $10^{\circ}$. Diese Scheibe wird an der Achse durch einen Steck- 
konus fixiert. Die Stütze der Scheiben trägt das Räderwerk mit der Übersetzung 1:25 und zwei Transmissionsscheiben für die Schnüre, mit deren Hilfe die Scheiben vom Helmholtz-Motor betrieben werden. Die stählernen Lager der ganzen Drehvorrichtung sind auf einem eisernen Ständer am Tische angeschraubt. Die Achse der Scheiben befindet sich in gleicher Höhe wie der Spalt $(S p)$, nämlich $23^{1 / 2} \mathrm{~cm}$ über dem Tische. Die Stellung der Scheiben ist eine solche, dass der Spalt mit einem horizontalen Radius koinzidiert, und zwar trifft das linksseitige Quadrat (Bild des extraordinären Strahles) auf den inneren Kreisring, das rechtsseitige Quadrat (Bild des ordinären Strahles) auf den äusseren Kreisring der Scheibe $\boldsymbol{I}$. Der die beiden Quadrate trennende dunkle Streifen von $6 \mathrm{~mm}$ Breite liegt zu beiden Seiten der Grenze der zwei Kreisringe. Da $D O(I I)$ um $2 \mathrm{~mm}$ grösser ist als $L O(I)$, so überdecken sich in dieser Grenzlinie die mittlere und vordere Scheibe, so dass längs derselben kein Spalt entsteht und also auch kein licht von dem nicht absolut dunkeln Trennungsstreifen der beiden Quadrate passieren kann. Durch diese Scheibenvorrichtung wird in der einfachsten Weise ermöglicht, einerseits die Grösse des äusseren und des inneren Sektors von $0-170^{\circ}$, andererseits ihre Differenz von $0-50^{\circ} \mathrm{zu}$ variieren, also absolute und relative Grösse der Reizdauer dementsprechend beliebig zu ändern; ferner kann die längere Dauer ganz nach Belieben dem rechtsseitigen oderlinksseitigen Reize verliehen werden, wasfür die Unbefangenheit des Urteiles von grösster Wichtigkeit ist. - Scheibe $I, I I$ und $I I I$ werden in eben dieser Reibenfolge auf die Achse aufgesteckt, $I$ zuhinterst in der Richtung des Strahlenganges, so dass die Gradeinteilung darauf während der Einstellung leicht abgelesen werden kann. Durch den äusseren Kreisring gelangt der rechtsseitige, durch den inneren der linksseitige Lichtreiz zum Beobachter. Die Scheiben drehen sich, vom Beobachter aus gesehen, im positiven Sinne. Einige Beispiele mögen die Kombinationsweise der drei Scheiben erläutern.

1. Die beiden Lichtreize sollen von gleicher Dauer sein: Man stellt Scheibe $I I$ so, dass $O E$ auf den Nullstrich fällt, also mit dem Ende des hakenförmigen Fortsatzes der Scheibe $I$ abschliesst. Dieser ist daher von der Scheibe $I I$ zugedeckt. Dahinter wird die Scheibe $I I I$ derart eingestellt, dass sie mit Scheibe $I$ den ganzen Kreis abschliesst, wobei sich die Scheiben $I$ und $I I I$ in einer Ausdehnung von $20^{\circ}$ bedecken, da jede dieser beiden Scheiben durch einen vollen Sektor von $190^{\circ}$ gebildet wird. In diesem Falle geht überhaupt kein Licht 
durch die Scheiben. Drehe ich nun die Scheibe $I I I$ im positiven Sinne (vom Experimentator aus, der neben der Lichtquelle steht), so entsteht ein freier Ausschnitt zwischen $O G$ der Scheibe $I I I$ und $A O$ der Scheibe $I$. Will ich nun die beiden Lichtreize gleich lang exponieren, so ist dies die hierzu nötige Einstellung. Soll z. B. die Dauer der Exposition $1^{0}$ der Scheibenumdrehung entsprechen, so liegen die Scheiben $I$ und $I I I$ derart übereinander, dass Winkel $A O G$ gleich $1^{\circ}$ ist. Scheibe $I$ und $I I I$ überdecken sich dann an ihrem anderen Ende (Winkel $C O F$ ) in einer Ausdebnung von 21 ${ }^{\circ}$. Die Grössen der Ausschnitte der Scheiben $I$ und $I I I$ müssen kleiner als $180^{\circ}$ sein, damit nicht bei völligem Abdunkeln des Lichtes oder bei ganz geringer Öffnung des Spaltes $D O L$ zwischen den beiden anderen Enden der beiden Sektoren $O F$ und $O C$ Licht hindurchdringt.

2. Es sei gewünscht, dass der rechtsseitige Lichtreiz länger dauere als der linke, z. B. rechts $20^{\circ}$, links $15^{\circ}$, also Differenz gleich $5^{\circ}$. Scheibe $I I I$ wird so lange im positiven Sinne (von der Lichtquelle aus) gedreht, bis $O G$ auf den Teilstrich 20 der Gradeinteilung fällt, also Winkel $A O G=20^{\circ}$ ist. Darauf wird Scheibe $I I$ aus ihrer Nullstellung (wobei $O E$ mit dem Radius $A O$ zusammenfällt) so verschoben, dass $O E$ auf Teilstrich $5^{0}$ fällt, also Winkel $A O E=5^{\circ}$. Winkel $E O G$ (innerer Ausschnitt) $=15^{\circ}$; folglich entsprechen die Ausschnitte den gewünschten Zeiten.

3. Es solle der linksseitige Lichtreiz länger dauern, und zwar wieder um $5^{\circ}$, also links 20 , rechts $15^{\circ}$. Nun stellt man Scheibe $I I I$ so ein, dass $O G$ auf Teilstrich $15^{\circ}$ fällt, also Winkel $A O G=15^{\circ}$; dann wird Scheibe $I I$ aus ihrer Nullstellung im negativen Sinne (vom Experimentator aus) gedreht, bis $O E$ auf $-5^{0}$ fällt, also Winkel $A O E=5^{\circ}$; dann ist Winkel $E O G=20^{\circ}$; der linksseitige Eindruck dauert demnach um $5^{0}$ länger als der rechtsseitige.

Die Grösse der einstellbaren Differenz beträgt $0-50^{\circ} ; D E$ (Scheibe $I I$ ) muss doppelt so gross sein, weil die eine Hälfte zur Deckung des hakenförmigen Ausschnittes in Scheibe $I$ verwendet wird. Die Einstellung wird dadureh möglichst genau gemacht, dass der Experimentator in der Richtung des betreffenden Radius, auf den er einstellt, visiert. Nach erfolgter Einstellung wird die Schraube, welche den vorderen Blechstern anpresst, angezogen und so die Stellung der drei Scheiben zu einander unverschiebbar gemacht. Das ganze Einstellungsmanöver währt etwa 1/2 Min. Die Einstellungs- 
vorrichtung ist sehr bequem zu handhaben. Die Scheibe $I V$ ist überhaupt unverschieblich eingestellt, und zwar so, dass auch bei Gebrauch des grössten Ausschnittes von $170^{\circ}$ volle Koinzidenz derselben mit dem Ausschnitte der Scheibe $1 \mathrm{~V}$ stattfindet. Dieser brauchte daher nur eine Grösse von 180:250 zu haben, also etwa $7^{\circ}$; der Sicherbeit halber wurde demselben eine Grösse von $10^{\circ}$ gegeben. Die Breite des Spaltbildes auf der vorderen Scheibe beträgt nicht ganz ${ }^{3} / 4^{0}$. Der Fehler, welcher dureh die für das Auf- und Abdecken des Lichtreizes vergehende Zeit erwächst, ist daher bei der raschen Umdrebung der Scheiben sehr gering.

Nach Passieren der Scheibenausschnitte gelangt das Licht in den Beobachterkasten ( $K$ Fig. 1). Dieser ist aus starkem Pappdeckel angefertigt und innen ganz mit schwarzem Tuchpapier ausgekleidet. Er ist $34 \mathrm{~cm}$ lang, $18 \mathrm{~cm}$ breit und $15 \mathrm{~cm}$ hoch und mit einem Holzschemel $(\boldsymbol{F}) 23^{1 / 2} \mathrm{~cm}$ über der Tischplatte angeordnet. De* Deckel ist abnehmbar; er schliesst den Kasten lichtdicht ab. Die Vorderwand des Kastens ist durch ein starkes geschwärztes Blech ersetzt, in dessen Mitte eine Röhre $\left(R_{2}\right)$ von $13 \mathrm{~cm}$ Länge und $5^{1 / 2} \mathrm{~cm}$ Durchmesser eingesetzt ist. Diese reicht so nahe als möglich an die hintere Scheibe $\left(S_{2}\right)$ heran und trägt an ihrem vorderen Ende eine aufsteckbare Messingfassung mit einer Konvexlinse von $12 \mathrm{D}\left(L_{2}\right)$. Die Röhre ist innen mit schwarzem Tuchpapier ausgekleidet und trägt oben und unten vertikal über einander je einen Längsfalz zum Einschieben einer Scheidewand aus starkem schwarzem Papier, welche vorne unmittelbar an die hintere Fläche der Linse $\left(L_{2}\right)$ angepasst ist uxd die ganze Röhre in zwei seitliche gleiche Teile teilt. Diese Scheidewand reicht $2 \mathrm{~mm}$ über die innere Fläche der vorderen Kastenwand. Den rückwärtigen Abschluss der Röhre bilden zwei Beinglasrechtecke $(B g)$, welche sich reehts und links mit ihren Kanten genau an die Scheidewand der Röhre anschliessen, so dass zwischen Beinglasplatten und Scheidewand kein Spalt frei bleibt. Die Beinglasplatten sind mit Hilfe einer Klebmasse an die innere Fläche der Kastenwand angeklebt und werden durch Holzleisten, die gegen die Seitenwände des Kastens gespreizt sind, an die Scheidewand angepresst. Die beiden inneren Kanten der Beinglasplatten sind gerade geschliffen und passen scharf aufeinander. Der Kasten ist so aufgestellt, dass das vom linken Quadrate ${ }^{1}$ ) durch den

1) Sieh S. 197. 
Spalt kommende Licht völlig in die linke Hälfte, das vom rechten Spalt kommende Licht völlig in die rechte Hälfte der Röhre fällt, wobei es vorher noch durch die Konvexlinse in einer Distanz von etwa $13 \mathrm{~cm}$ zu zwei Kreisen von ungefähr $12 \mathrm{~mm}$ Durchmesser gesammelt wird, welche sich mit ihren medialen Anteilen überdecken würden, wenn nicht die Scheidewand dies verhinderte. Es wird also gerade auf den beiden Beinglasplatten rechts und links je ein Kreissegment von etwa $6 \mathrm{~mm}$ Radius und $10 \mathrm{~mm}$ Breite abgebildet, welche nur durch die Scheidewand getrennt sind, die sich von vorn wie ein schwarzer Strich ausnimmt. Aus diesen beiden Lichtkreisen ist ein Kreis von $8 \mathrm{~mm}$ ausgeschnitten, und zwar auf folgende Weise: Mit Hilfe eines Locheisens wurde aus steifem schwarzen Papier ein kreisrundes Loch von $8 \mathrm{~mm}$ ausgeschlagen, dasselbe genau halbiert und je eine schwarze Papierplatte mit dem halbkreisförmigen Ausschnitte rechts und links von der Scheidewand an die innere Fläche der Beinglasplatten angeklebt, so dass die beiden Halbkreise zusammen wie ein Kreis von $8 \mathrm{~mm}$ Durchmesser aussehen, welcher durch eine vertikale Linie in zwei Halbkreise geteilt ist. Das Licht wird durch die Beinglasplatten völlig homogen zerstreut. Die Beobachtung soll ergeben, welcher der beiden Halbkreise während der Beleuchtung heller erscheint. Der Beinglasschirm ist ebenfalls so wie die Röhre durch die Scheidewand geteilt, damit nicht durch Dispersion innerhalb der Beinglasplatten falsches Licht von der rechten in die linke Hälfte gelange $\left.{ }^{1}\right)$. Genau längs der Scheidewand ist die Fixationsmarke $(F m)$ angebracht: ein sehr dünner Platindraht von $1 \mathrm{~cm}$ Länge, welcher, oben und unten von zwei dicken Kupferzuleitungsdrähten gebalten, durch einen Akkumulator zum Glühen gebracht wird. Durch Handhaben eines Vorschaltwiderstandes kann die Mitte desselben in einer Länge von etwa $4 \mathrm{~mm}$ gerade in dunkler Rotglut von beliebiger Intensität erhalten werden.

In der vorderen Wand des Kastens ist eine für beide Augen bestimmte querovale Öffnung angebracht, welche von einem Pappdeckelansatze $(V)$ umgeben ist, dessen vorderer Umriss sich

1) Dadurch entsteht allerdings zu beiden Seiten der Scheidewand auf der Vergleichsfläche ein dunklerer Streifen; jeder Punkt der Beinglasplatte empfängt nämlich seine Bestrablung nicht bloss direkt von der Lichtquelle, sondern auch durch Diffusion aus seiner Nachbarschaft. Dieser letztere Betrag entfällt längs der Scheidewand. Er ist bei dünnen Beinglasplatten geringer als bei dickeren. Hieraus ergibt sich der Vorzug der früher erwähnten Foucault'schen Schírme wegen der Dünnheit der diffundierenden Schicht. 
an die Gesichtsform des Beobachters anpasst, also an der Stirn rund, an der Nase mit einem entsprechenden Einschnitte versehen ist. Der Beobachter lehnt seinen Kopf daran und betrachtet die Fixationsmarke, bis der Reiz erscheint. In der Reizpause lässt er den Blick im absolut dunklen Kasten herumschweifen. Das Zimmer wird während der Versuche gänzlich abgedunkelt. Eine Baltzar'sche Stromunterbrechungsuhr gibt in Verbindung mit einer elektrischen Signalklingel alle 3 oder 5 Sek. ein Zeichen. Die Lampe, welche zur Adaptation in den Reizpausen dient, wird mit Hilfe eines Selbstzünders angezündet. Die nötigen Manipulationen besorgt der Experimentator beim Licht einer elektrischen Taschenlaterne.

Die beschriebene Versuchsanordnung hat sich erst allmählich aus vielen Vorversuchen und nach manchen Abänderungen entwickelt; ich halte es für überflüssig, die weniger vollkommenen $\mathrm{Zu}$ sammenstellungen hier zu erörtern. Auch will ich bemerken, dass sich die ganze Versuchsanordnung bedeutend vereinfachen lässt, wenn man auf den Spalt zur momentanen Belichtung verzichtet.

Die Ausführung meiner Versuche geschah meistens in der Zeit von drei bis fünf Uhr nachmittags, manchmal auch vormittags. Es waren natürlich immer zwei Personen nötig, der Beobachter und der Experimentator, welcher die Scheibenausschnitte einstellte und die Aufzeichnungen machte. Beide wechselten $a b$, und zwar ungefähr jede halbe Stunde, je nach der Disposition des Beobachters. Nach der Instandsetzung des Motors wurde die Umdrehungszahl der schnelllaufenden Scheibe während einiger Minuten gezählt, wobei sich fast nie Unregelmässigkeiten ergaben. Eine raschere oder langsamere Bewegung der Scheibe wurde durch Änderung der Einstellung des Regulators oder der Transmissionen erzielt. Dann wurde die Stromunterbrechungsuhr in Gang gesetzt, die Lampe zur Helladaptation angezündet und die Balken der Fenster geschlossen. Im Verlaufe dieser Vorbereitungen versehwanden meistens schon die Nachbilder, welche der Beobachter aus dem Freien mit sich brachte. Dieser setzte sich nun vor den Beobachtungskasten und blickte durch die "Adaptationsbrille" 1 bis 2 Min. nach der mit einer Beinglaskugel umgebenen Auerlampe. Unterdessen stellte der Experimentator die Sektoren ein, setzte sodann den Motor in Gang und drehte schliesslich die zur Helladaptation verwendete Auerlampe $a b$. Nun wendete sich der Beobachter zum Kasten und stützte den Kopf gegen die beschriebene Stütze, schloss selbst den 
die Fixationsmarke durchlaufenden Strom und fixierte jene. Nach dem Aufleuchten des Kreises hatte der Beobachter sein Urteil über das Helligkeitsverhältnis der beiden Halbkreise abzugeben, welches vom Experimentator in eine bereitgehaltene Tabelle eingetragen wurde. Der Beobachter blickte in den Kasten, bis der Lichtreiz viermal wiedergekehrt war, was in einer Pause von je 4 bis 18 Sek. geschah, so dass sich die Adaptation währenddessen nicht merklich änderte. Blickte der Beobachter länger in den Dunkelkasten als 1 bis $1 \frac{1 / 2}{2}$ Minuten, so zeigte sich die Veränderung des Adaptationszustandes darin, dass ihm darnach die dargebotenen Reize viel dunkler vorkamen. Diese von mir und allen meinen Mitarbeitern gemachte Beobachtung erklärt sich wahrscheinlich aus der fovealen Lage der Vergleichsfelder. Nach vier Versuchen wurde wieder die Adaptationslampe angezundet, nach welcher der Beobachter durch die Adaptationsbrille zu schauen hatte, bis der Experimentator mit der Aufzeichnung der Beobachtungsergebnisse in den Tabellen und der Neueinstellung der Scheibenausschnitte fertig war usf.

Während der Zwischenpausen zwischen den Darbietungen der Lichtreize achtete der Beobachter auf die Glockenzeichen, welche von der Stromuhr ausgelöst wurden. Die Spaltbreite betrug nur etwa $1 / 5 \mathrm{~mm}$, genau $0,214 \mathrm{~mm}$. Es ergibt sich hieraus die geringe absolute Helligkeit der Vergleichsfelder.

Die erste Aufgabe galt nun der Gleichstellung der Helligkeit der beiden Reizflächen. Diese wurde in folgender Weise vorgenommen: Zuerst wurde grob verglichen, ob sich bei beliebig langer Beobachtung schon eine Verschiedenbeit zwisehen den beiden Hälften zeigte, und zwar erschien eine Verschiedenheit der Helligkeit meistens auch als eine Verschiedenheit des Farbentones. Nachdem sich Beobachter und Experimentator von dem Vorhandensein derselben überzeugt hatten, wurde sie durch Drehung des Kalkspatprismas oder durch sehr geringe Verschiebung der Beinglasplatten im Beobachtungskasten mit der zwischen ihnen eingeklemmten Scheidewand, so gut es ging, ausgeglichen. War dann bei gewöhnlicher Beobachtung keine Versehiedenheit mehr bemerkbar, so wurden die beiden Kreishälften während irgendeiner untermaximalen Zeit gleichzeitig beleuchtet, und der Beobachter hatte zu entscheiden, ob der rechte und der linke Halbkreis gleich hell seien.

Damit er sein Urteil unbeeinflusst abgebe, wurden viele Vexierversuche angestellt, indem der Experimentator den äusseren oder 
inneren Scheibenausschnitt um so vieles grösser einstellte, dass hierdurch bereits ein merklicher Helligkeitsunterschied zwischen den beiden Halbkreisen auftrat. Das Urteil "gleich" wurde selten ausgesprochen, und es zeigte sich als das beste erzielbare Resultat, wenn während mehrerer Versuche von möglichst vielen Beobachtern ebenso oft "rechts heller" wie "links heller" oder "unbestimmt" angegeben wurde, so dass sich diese Angaben die Wage hielten und das Durchschnittsergebnis "unbestimmt" war. Dann wurde die dritte und feinste Gleichstellungsmethode angewendet, und zwar in folgender. Weise :

Ich will den einen Halbkreis mit $A$, den anderen mit $B$, die Expositionszeit mit $E$. $Z$. bezeichen. $A$ wird gerade um ein so grosses Zeitteilchen $\tau$ (= zeitliche Unterschiedsschwelle) vor $B$ exponiert, dass es beim gleichzeitigen Verschwinden mit $B$ heller erscheint:

$$
\begin{aligned}
& \text { E. Z. von } A=t+\tau \\
& \text { E. } Z \text {. von } B=t
\end{aligned}
$$

Nun wird $B$ um das gleiche Zeitteilchen $\tau$ länger exponiert als $A$ : E.Z. von $A=t$, von $B=t+\tau$.

Das Urteil kann nun lauten: 1. $B=$ (ebenso hell wie) $A$ oder

2. ? (unbestimmt) oder

3. $B$ heller als $A$.

Im Falle 1. und 2. ist die objektive Helligkeit von $B$ kleiner als von $A$, im Falle 3 . ist sie entweder gleich oder grösser als die von $A$. Was von beidem der Fall ist, wird auf folgende Weise entschieden: die Expositionszeit von $B(t+\tau)$ wird um so viel $(=\varepsilon)$ vermindert, dass $B$ gerade noch heller erscheint als $A$, dessen E. $Z$. $=t$ ist $(E . Z$. von $B=t+\tau-\varepsilon)$; ist $\varepsilon=0$, d. h. erscheint $B$ bei der geringsten Verkleinerung seiner Expositionszeit $(t+x)$ nicht mehr heller als $A$, so ist $B=A$, d. b. die objektive Helligkeit von $B$ gleich der von $A$; ist $\varepsilon>0$, so ist auch $B>A$, d. h. die objektive Helligkeit von $B$ grösser als von $A$, und zwar um so grösser, je grösser $\varepsilon$ ist.

Diese photometrisehe Methode der Vergleichung untermaximaler Lichtreize mit an der Schwelle liegenden zeitlichen Differenzen, - ich will sie Differenzialmethode nennen - erwies sich als die sicherste. Allerdings erfordert sie Geduld, Zeit und Übung. Bei ihrer Anwendung zeigte sich mir und allen meinen Mitarbeitern mit Sicherheit die weitaus grössere Genanigkeit dieser Methode 
gegenüber der bisher gebräuchlichen photometrischen Vergleichsmethode ohne Berücksichtigung der Expositionsdauer.

Für die vorliegende Aufgabe war eine möglichst genaue Gleichstellung der beiden Reizfeldbelligkeiten natürlich die wichtigste Grundlage.

Die ersten Versuchsreihen wurden noch mit einer unvollkommenen VVersuchsanordnung angestellt, - bei der das durch den Spalt gesendete Licht durch eine einfache räumliche Vorrichtung halbiert wurde, indem der Spalt in der Mitte durch eine Scheidewand in zwei Teile geteilt war und die Länge der beiden Teile so lange abgeändert wurde, bis die beiden Halbkreise gleich hell erschienen. Wäre die Lichtverteilung auf dem Spalte eine ganz gleichmässige gewesen, so hätten natürlich die Spalthälften genau gleich sein müssen. Dies war aber nicht der Fall, sondern es musste der eine Spaltteil um Bruchteile eines Millimeters länger gewählt werden als der andere, damit die beiden Halbkreise gleich hell erschienen. Da schon so geringe Verschiedenheit in der Spaltlänge rechts und links eine merkbare Verschiedenheit in der Helligkeit der beiden Reizfelder ergab, so war diese Art der Gleichstellung selbstverständlich eine sehr unsichere und musste fortwährend nachgeprüft werden.

Die überwiegende Mehrzahl der Versuche wurde von mir im Vereine mit Herrn cand. med. E. Guggenberger angestellt. Wir suchten die geringste zeitliche Differenz, welche noch zu einem merklichen Helligkeitsunterschiede zwischen den beiden Halbkreisen führte. Aus 416 Versuchsreihen zu je vier Beobachtungen, welche aus der ursprünglichen Versuchsanordnung hervorgingen, ergeben sich die in Tabelle I mitgeteilten Resultate.

Tabelle I.

\begin{tabular}{|c|c|c|}
\hline Versuchspersonen & $\begin{array}{l}\text { Dauer } \\
\text { des längeren } \\
\text { Lichtreizes } \\
\text { in Sekunden }\end{array}$ & $\begin{array}{l}\text { Schwellen- } \\
\text { differenz } \\
\text { in Sekunden }\end{array}$ \\
\hline $\begin{array}{ccc}\text { cand. pharm. Becher und } \\
\text { Stigler. . . . * · } \text {. } \\
\text { Guggenberger und Stigler } \\
" & " & " \\
" & " & " \\
" & " & " \\
" & " & "\end{array}$ & $\begin{array}{l}0,014 \\
0,056 \\
0,08 \dot{3} \\
0, \dot{1} \\
0,14 \\
0,167 \\
0,194\end{array}$ & $\begin{array}{l}0,0014 \\
0,0042 \\
0,005 \\
0,007 \\
0,01(?) \\
0,0125 \\
0,0125\end{array}$ \\
\hline
\end{tabular}


Wegen der lästigen Notwendigkeit einer fortwährenden Nachprüfung der objektiven Gleichheit der beiden Reizfeldhelligkeiten gingen wir nach dreimonatlicher Arbeit zu der neuen oben besebriebenen Versuchsanordnung über.

\section{Teil. Versuche über die Maximalzeit.}

Vor allem wurde nach der oben angegebenen Methode die Gleichstellung der objektiven Helligkeit der beiden Reizfelder in sehr zahlreichen Versuchen vorgenommen. Nachher stellten wir allgemeine Orientierungsversuche über die Maximalzeit an. Da sich dieselben auch auf grössere Zeiten erstrecken sollten, wurde die langsam gehende Scheibe vom Apparate entfernt, so dass der Lichtreiz während jeder Umỏrehung der rascheren Scheibe einmal wiederkehrte. Diese erhielt durch Anwendung von Transmissionsvorrichtungen auf einem Vorgelege eine solche Geschwindigkeit, dass alle 4 Sek. eine Umdrehung erfolgte, so dass also einem Ausschnitte von $1^{0}$ eine Lichtreizdauer von 0,01 Sek. entsprach. Der Lichtreiz kehrte alle 4 Sek. wieder.

Nach je vier Versuchen hatte der Beobachter sein Auge wieder bis zur Vollendung der nächsten Einstellung hell zu adaptieren. Zuerst wurde die geringste zeitliche Differenz der beiden Lichtreize bestimmt, welche bereits hinreichte, um zu bemerken, dass die beiden Halbkreise nicht gleichzeitig erschienen. Guggenberger und Stigler fanden unter den gegebenen Versuchsbedingungen, dass bei einer Differenz von 0,024 Sek. noch nicht bemerkt wurde, dass der eine Halbkreis früher erschien als der andere, dass hingegen bei einer Differenz von 0,028 Sek. dies schon deutlich und sicher wahrgenommen wurde. Petrèn's längste Expositionszeit für Weiss war 0,2859 Sek. mit einer Schwelle von $\frac{1}{11,34}$. Daraus geht hervor, dass die zeitliche Differenz im Beginne der beiden zu vergleichenden Lichtreize in diesem Falle 0,025 Sek. betrug, und dies war auch die grösste aus seiner Kurve berechenbare Differenz. 'Bei grösseren Differenzen sah auch Petrèn schon eine "Hakenfigur". Diese Angabe stimmt also recht genau mit der unseren überein.

Exner hatte etwas kleinere Differenzen anwenden müssen, um die Wahrnehmung des nicht gleichzeitigen Erscheinens der beiden Halbkreise zu vermeiden, und zwar für die grösste verwendete Intensität 0,0169 . für die kleinste 0.0193 Sek. Dies erklärt sich 
leicht daraus, dass Exner weit grössere Reizflächen verwendete, wobei die getrennte Wahrnehmung, offenbar auch zufolge der grösseren Helligkeit, leichter eintrat.

Aus den zur Feststellung der Maximalzeit vorgenommenen Orientierungsversuchen, von denen wir 235 Reihen verzeichneten, gebe ich die der Versuchsperson H. in der Tabelle II wieder. In den Originaltabellen wurden die Versuchsergebnisse in Graden der Sektorenbreite angegeben, welche ich hier in Zeit umgerechnet habe. Die Angabe der Versuchsperson: "rechts heller" bringe ich durch "r", "links heller" durch "l", "gleich" durch "=-", "unbestimmt" durch n?" zum Ausdrucke.

\section{Tabelle II.}

Beobachter: stud. techn. Honigl. 21. und 22. Mai 1907. 1 U. in 4 Sek.; $1^{0}=0,0 \mathrm{i}$ Sel., Alle 4 Sek. ein Lichtreiz.

\begin{tabular}{|c|c|c|c|c|c|c|c|c|}
\hline \multirow{2}{*}{ Nr. } & \multicolumn{2}{|c|}{$\begin{array}{c}\text { Daner des Lichtreizes } \\
\text { in Sek. }\end{array}$} & \multirow{2}{*}{$\begin{array}{l}\text { Differenz } \\
\text { in Sek. }\end{array}$} & \multirow{2}{*}{\multicolumn{4}{|c|}{ Beobachtungen }} & \multirow[t]{2}{*}{ Mittel } \\
\hline & links & rechts & & & & & & \\
\hline 1 & $0,0 \dot{8}$ & 0,07 & $0,0 \dot{1}$ & 7 & $l$ & $l$ & 7 & $l$ \\
\hline 2 & $0,0 \dot{7}$ & $0,0 \dot{8}$ & 0,01 . & $r$ & $r$ & $r$ & $r$ & $r$ \\
\hline 3 & 0,2109 & 0,2 & $0,0 \mathbf{i}$ & $r$ & $r$ & $r$ & $r$ & $r$ \\
\hline 4 & 0,216 & 0,226 & $0,0 \mathrm{i}$ & $r$ & $r$ & $r^{*}$ & $r$ & $r$ \\
\hline 5 & 0,239 & 0,222 & 0,01 & $l$ & $l$ & 7 & $l$ & $l$ \\
\hline 6 & $0, \dot{3}$ & 0,316 & 0,017 & $l$ & $l$ & $l$ & 7 & $l$ \\
\hline 7 & $0, \dot{3}$ & 0,355 & $0,0 \dot{2}$ & $r$ & $v$ & $r$ & $r$ & $r$ \\
\hline 8 & 0,355 & $0, \dot{3}$ & 0,02 & $l$ & $l$ & $l$ & 7 & $l$ \\
\hline 9 & 0,866 & $0, \dot{8}$ & $0,0 \dot{2}$ & $r$ & $r$ & $r$ & $r$ & $x^{*}$ \\
\hline 10 & 0,8 & 0,866 & $0,0 \dot{2}$ & $l$ & 7 & $l$ & $l$ & 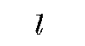 \\
\hline 11 & $0, \dot{8}$ & 0,866 & $0,0 \dot{2}$ & $l$ & $l$ & 7 & $l$ & $l$ \\
\hline 12 & 1,3098 & 1,332 & $0,0 \dot{2}$ & $r$ & $r$ & $r$ & $r$ & $r$ \\
\hline 13 & 1,665 & 1,6317 & $0,0 \dot{3}$ & $l$ & $l$ & $l$ & $l$ & $l$ \\
\hline 14 & 1,6317 & 1,665 & $0,0 \dot{3}$ & $r$ & $r$ & r & $r$ & $r$ \\
\hline
\end{tabular}

Aus je vier aufeinanderfolgenden Angaben wurde, der besseren Übersicht halber, das arithmetische Mittel in die Tabelle eingesetzt. Die in Tabelle II enthaltenen Angaben wurden von der Versuchsperson H. mit aller Bestimmtheit gemacht. Ich habe einige Male die Stellung der Sektoren nacheinander unverändert gelassen (wie dies auch einmal in der Tabelle angeführt ist) und auf diese Weise Kontrollversuche ausgeführt, welche aber stets wieder zu gleichen Aussagen führten. Aus dieser Tabelle geht hervor, dass der Versuchsperson H. bis zur Expositionsdauer von 0,233 Sek. eine zeit- 
Über die Unterschiedsschwelle im aufsteig. Teile einer Lichtempfindung. 207

liche Differenz von 0,01 Sek., bis zur Expositionszeit von 1,3 Sek. eine Differenz von $0,0 \dot{2}$ Sek. und bis zur Expositionszeit von 1,63 Sek. eine Differenz von 0,03 Sek. völlig zur Unterscheidung der beiden Helligkeiten genügten, und dass dabei stets der länger belichtete Halbkreis heller erschien. Bei der Differenz von 0,02 Sek. schienen die beiden Halbkreise gleichzeitig anfzutreten, bei einer Differenz von $0,0 \dot{3}$ Sek. erkannte H., dass der eine Halbkreis früher erschien. Aus diesem Grunde könnten die beiden letzten Reihen der Tabelle II Zweifel erwecken. Gegen alle anderen Reihen aber bis zur Expositionszeit von 1,3 Sek. lässt sich tleser Einwand nicht erheben. H. wurde stets aufmerksam gemacht, besonders darauf zu achten, ob nicht der eine Halbkreis zuerst heller, im Momente des Verschwindens des ganzen Kreises aber dunkler erscheine als der andere. Dies wurde stets bestimmt verneint.

In Tabelle III gebe ich die Beobachtungsresultate meines weitaus geübtesten Mitarbeiters G ug g en b erger wieder.

Tabelle III.

Beobachter Guggenberger. 6. Juli 1907. 100 U. in 144 Sek.; daher $1^{0}$ $=0,004$ Sek. Alle 9 Sek. ein Lichtreiz.

\begin{tabular}{|c|c|c|c|c|c|c|c|c|}
\hline \multirow{2}{*}{$\mathrm{Nr}$. } & \multicolumn{2}{|c|}{ Reizdauer in Sek. } & \multirow{2}{*}{$\begin{array}{c}\text { Differenz } \\
\text { in Sek. }\end{array}$} & \multirow{2}{*}{\multicolumn{4}{|c|}{ Beobachtungen }} & \multirow{2}{*}{ Mittel } \\
\hline & links & rechts & & & & & & \\
\hline 1 & 0,34 & 0,36 & 0,02 & $y^{*}$ & $r$ & $l$ & $l$ & ? \\
\hline 2 & 0,36 & 0,34 & 0,02 & $i$ & $i$ & $l$ & $i$ & $\dot{l}$ \\
\hline 3 & 0,36 & 0,34 & 0,02 & $r$ & $r$ & $r$ & $r$ & $r$ \\
\hline 4 & 0,36 & 0,36 & - & $r$ & $l$ & ? & $l$ & $?$ \\
\hline 5 & 0,36 & 0,94 & 0,02 & l & $l$ & $i$ & $l$ & $\dot{l}$ \\
\hline 6 & 0,34 & 0,36 & 0,02 & $r$ & $r$ & $r$ & $r$ & $r$ \\
\hline 7 & 0,56 & 0,528 & 0,032 & 7 & 7 & $l$ & $l$ & $l$ \\
\hline 8 & 0,528 & 0,56 & 0,032 & $r$ & $r$ & $r$ & $r$ & $r$ \\
\hline 9 & 0,612 & 0,64 & 0,028 & $r$ & $r$ & $r$ & $r$ & $r$ \\
\hline 10 & 0,64 & 0,616 & 0,024 & 7 & $i$ & $l$ & $i$ & l \\
\hline 11 & 0,64 & 0,616 & 0,024 & 7 & $i$ & $l$ & $l$ & $l$ \\
\hline 12 & 0,64 & 0,64 & - & $l$ & $=$ & $r$ & $r$ & ? \\
\hline 13 & 0,656 & 0,68 & 0,024 & $r$ & $r$ & $r$ & $r$ & $r$ \\
\hline 14 & 0,68 & 0,656 & 0,024 & $i$ & $i$ & l & li & $i$ \\
\hline 15 & 0.68 & 0,656 & 0,024 & l & $i$ & $l$ & $l$ & $l$ \\
\hline 16 & 0,656 & 0,68 & 0,024 & $r$ & $r$ & $r$ & $r$ & $r$ \\
\hline 17 & 0,66 & 0,68 & 0,02 & $r$ & $r$ & $r$ & $r$ & $r$ \\
\hline 18 & 0,68 & 0,66 . & 0,02 & $=$ & $l$ & $i$ & $l$ & $i$ \\
\hline 19 & 0,68 & $0,664^{\circ}$ & 0,016 & $l$ & $i$ & $r$ & l & $i$ \\
\hline 20 & 0,664 & 0,68 & 0,016 & $l$ & $i$ & $r$ & $r$ & $?$ \\
\hline 21 & 0,664 & 0,68 & 0,016 & $l$ & $?$ & $r$ & ? & ? \\
\hline
\end{tabular}

Ich habe auch die Wiederholung einzelner Versuche und die eingeschalteten Vexierversuche in diese Tabelle aufgenommen, um 
damit zu zeigen, in welcher Weise die Versuche überhaupt vorgenommen wurden. Natürlich blieb der Beobachter immer ohne Kenntnis der Versuchseinstellung. Bei gleicher Dauer der beiden Reize zeigten sich fast immer ganz charakteristisch solche Angaben des Beobachters, dass im Mittel daraus „unbestimmt" resultierte. Ein Gleichheitsurteil wurde nur sehr selten ausgesprochen, offenbar, weil der Beobachter bereits von dem Vorurteil befangen war, es müsse die eine Hälfte heller als die andere erscheinen. Das Mittel "unbestimmt" ist daher als das beste Resultat bei Darbietung gleicher Lichtreize zu betrachten und beruht weder auf einem Fehler der. Versuchsanordnung noch auf Unaufmerksamkeit des Beobachters. Die Wiederholung der gleichen Einstellung mehrere Male hintereinander hat sich deshalb als günstig erwiesen, weil der Beobachter leicht in Versuchung kam, zu erwarten, dass die längere Reizdauer abwechselnd rechts und links eingestellt würde. Durch solche Vexierversuche wollten wir den Beobachter daran gewöhnen, möglichst vorurteilsfrei in den Kasten zu schauen.

Bei den in Tabelle III mitgeteilten Versuchen war wieder die langsame Scheibe verwendet worden, so dass der Lichtreiz nach je $25 \mathrm{Um}-$ drehungen der rascheren Seheibe wiederkehrte. Helm holtz-Motor und Transmissionseinrichtungen wurden so eingestellt, dass $100 \mathrm{Um}$ drehungen der raschen Scheibe in 144 Sek. erfolgten. $1^{0}$ entsprach daher einer Zeit von 0,004 Sek. und alle 9 Sek. kehrte der Lichtreiz wieder. Die Stromunterbrechungsuhr gab alle 3 Sek. mit Hilfe der elektrischen Klingel ein kurzes Zeichen, so dass der Beobachter sich in der Pause damit zu beschäftigen hatte, diese Zeichen zu zählen und vor dem Herannahen des dritten Zeichens die Fixationsmarke ins Auge zu fassen. Da bei einer Differenz von mebr als 0,024 Sek. bereits das getrennte Auftreten der beiden Halbkreise wahrgenommen wurde, so könnte den Versuchsreihen 7, 8, 9 Voreingenommenheit des Beobachters zum Vorwurf gemacht werden; aber auch ohne diese Reihen geht aus der Tabelle zur Genüge hervor, dass eine zeitliche Differenz von 0,02 Sek. für alle Expositionszeiten bis zur höchsten hier verwendeten von 0,68 Sek. veranlasste, dass der Beobachter Guggenberger den früher belenchteten Halbkreis beim Versehwinden für heller hielt als den später erschienenen. Bei einer Differenz von 0,016 Sek. treten bei der Expositionszeit von 0,68 Sek. bereits unbestimmte Angaben auf, so dass diese Differenz hiefür als unterschwellig anzusehen ist. Guggenberger batte 
Über die Unterschiedsschwelle im aufsteig. Teile einer Lichtempfindung. 209

sein Hauptaugenmerk auf den Moment des Verschwindens zu richten. Eine Umkehr der anfänglich grösseren Helligkeit wurde dabei von Guggenberger am länger beleuchteten Halbkreise ebensowenig bemerkt wie von Honigl.

Tabelle IV.

Beobachter Stigler: 21.-28. Mai 1907. 1 U. in 4 Sek.; $1^{0}=0,0 \mathrm{i}$ Sek. Alle 4 Sek. ein Lichtreiz.

\begin{tabular}{|c|c|c|c|c|c|c|c|c|}
\hline \multirow{3}{*}{$\begin{array}{c}\text { Nr. } \\
1\end{array}$} & \multicolumn{2}{|c|}{ Reizdauer in Sek. } & \multirow{3}{*}{$\begin{array}{c}\text { Differenz } \\
\text { in Sek. } \\
0,0166\end{array}$} & \multirow{2}{*}{\multicolumn{4}{|c|}{ Beobachtungen }} & \multirow{3}{*}{$\frac{\text { Mittel }}{r}$} \\
\hline & \multirow{2}{*}{$\frac{\text { links }}{0,1499}$} & \multirow{2}{*}{$\frac{\text { rechts }}{0,1665}$} & & & & & & \\
\hline & & & & $r$ & $r$ & $r$ & $r$ & \\
\hline 2 & 0,1776 & 0,1665 & $0,0 \mathrm{i}$ & $l$ & $l$ & $l$ & $?$ & $l$ \\
\hline 3 & 0,1665 & 0,1776 & $0,0 \mathrm{i}$ & $r$ & $r$ & $r$ & $r$ & $r$ \\
\hline 4 & 0,1943 & 0,2054 & $0,0 \mathrm{i}$ & $r$ & $r$ & $r$ & $=$ & $r$ \\
\hline 5 & 0,2054 & 0,2165 & $0,0 \dot{1}$ & $r$ & $r$ & $r$ & $r$ & $r$ \\
\hline 6 & $0, \dot{2}$ & 0,2165 & 0,0057 & $=$ & ? & $r$ & $l$ & $?$ \\
\hline 7 & 0,2054 & $0, \dot{2}$ & 0,0168 & $r$ & $r$ & $r$ & $r$ & $r$ \\
\hline 8 & $0, \dot{2}$ & 0,2054 & 0,0168 & $l$ & $l$ & $l$ & $l$ & $l$ \\
\hline 9 & $0,2 \dot{1}$ & $0, \dot{2}$ & $0,0 \dot{1}$ & $r$ & $r$ & $r$ & $r$ & $r$ \\
\hline 10 & $0, \dot{2}$ & $0,2 \dot{1}$ & $0,0 \mathbf{i}$ & $l$ & $?$ & $l$ & $=$ & $?$ \\
\hline 11 & 0,2276 & $0,2 \dot{1}$ & 0,0165 & $l$ & $l$ & $l$ & $i$ & $l$ \\
\hline 12 & 0,233 & 0,21 & $0,0 \dot{2}$ & 7 & $l$ & $l$ & $l$ & $l$ \\
\hline 13 & 0,233 & $0, \dot{2}$ & 0,01 & $l$ & $l$ & $l$ & $=$ & $l$ \\
\hline 14 & $0,2 \dot{4}$ & 0,233 & $0,0 \mathrm{i}$ & $r$ & $r$ & $l$ & $l$ & $?$ \\
\hline 15 & 0,272 & $0,2 \dot{5}$ & $0,01 \hat{6}$ & 7 & $=$ & $l$ & $=$ & $?$ \\
\hline 16 & $0,2 \dot{7}$ & 0,272 & 0,005 & $l$ & $l$ & $l$ & $l$ & $l$ \\
\hline 17 & 0,27 & $0,2 \dot{7}$ & - & $r$ & $r$ & $=$ & $=$ & $?$ \\
\hline 18 & $0,2 \dot{7}$ & $0,2 \dot{7}$ & - & $?$ & $=$ & $r$ & $?$ & $?$ \\
\hline 19 & 0,27 & $0,2 \dot{7}$ & - & $r$ & 7 & $=$ & 7 & $?$ \\
\hline 20 & $0,2 \dot{7}$ & $0,2 \dot{8}$ & $0,0 \dot{1}$ & ? & $?$ & 7 & $l$ & $?$ \\
\hline 21. & $0,2 \dot{8}$ & 0,272 & $0,01 \dot{6}$ & $l$ & $l$ & $l$ & $l$ & $l$ \\
\hline 22 & $0,2 \dot{8}$ & $0,2 \dot{7}$ & 0,01 & $l$ & $l$ & $l$ & $l$ & $l$ \\
\hline 23 & $0,3 \dot{2}$ & $0, \dot{3}$ & 0,01 & $r$ & $r$ & $r$ & $r$ & $r$ \\
\hline 24 & $0,3 \dot{2}$ & $0, \dot{3}$ & 0,01 & $r$ & $r$ & $r$ & $r$ & $r$ \\
\hline 25 & $0, \dot{3}$ & $0, \dot{3}$ & - & $?$ & $=$ & 7 & $?$ & ? \\
\hline 26 & $0,3 \dot{4}$ & $0, \dot{3}$ & $0,0 \dot{1}$ & $l$ & $l$ & $=$ & $l$ & $l$ \\
\hline 27 & 0,37 & $0, \dot{8}$ & $0,0 \mathrm{i}$ & $r$ & $=$ & $r$ & $r$ & $r$ \\
\hline 28 & 0,37 & $0,3 \dot{8}$ & $0,0 \mathrm{i}$ & $=$ & $=$ & $=$ & $=$ & $=$ \\
\hline 29 & $0,3 \dot{7}$ & $0,3 \dot{8}$ & $0,0 \dot{1}$ & $r$ & $=$ & $=$ & $=$ & $=$ \\
\hline 30 & 0,394 & 0,372 & $0,0 \dot{2}$ & $l$ & $?$ & $=$ & $r$ & $?$ \\
\hline 31 & 0,394 & 0,372 & $0,0 \dot{2}$ & $r$ & $=$ & $=$ & $l$ & ? \\
\hline 32 & 0,394 & 0,372 & $0,0 \dot{2}$ & $l$ & 7 & $?$ & 7 & $l$ \\
\hline 33 & 0,394 & 0,372 & $0,0 \dot{2}$ & $=$ & $=$ & $=$ & $r$ & $=$ \\
\hline 34 & 0,39 & $0,3 \dot{8}$ & $0,0 \dot{1}$ & $r$ & $l$ & $l$ & 7 & $l$ \\
\hline 35 & $0,3 \dot{9}$ & $0,3 \dot{8}$ & $0,0 \dot{1}$ & $=$ & $=$ & $=$ & $=$ & $=$ \\
\hline 36 & $0,4 \dot{1}$ & $0,3 \dot{8}$ & $0,0 \dot{2}$ & $=$ & $?$ & $r$ & $?$ & $?$ \\
\hline
\end{tabular}


In Tabelle IV teile ich einige der von mir selbst gemachten Beobachtungen mit. Ich habe in dieser Tabelle die Expositionszeiten der Übersicht halber der Grösse nach geordnet; hei den Versuchen wurde diese Reihenfolge nicht eingehalten. Wiederum habe ich Vexierversuche mit Gleichstellung der beiden Reizdauern in die Tabelle mit aufgenommen, um darzutun, dass tatsächlich bei gleicher Dauer der beiden Lichtreize das Durehschnittsresultat von vier Beobachtungen immer "unbestimmt" lautete, wodurch wieder die beste Garantie für möglichste objektive Gleichheit der beiden Lichtreize geboten, andererseits auch die Unbefangenheit des Beobachters erwiesen wurde. Aus Tabelle IV geht hervor, dass für mich bis zur Expositionszeit von 0,34 Sek. (Versuchsreihen 1-26) eine Differenz von 0,01 Sek. genügte, um den länger dauernden Lichtreiz als heller wahrzunehmen. Die Reihen 27-29 zeigen, dass für eine Expositionszeit von 0,38 Sek. eine Differenz von 0,0i Sek. unter zwölf Beobachtungen nur mehr viermal wahrgenommen wurde; in den übrigen Fällen hatte der Beobachter den Eindruck der Gleichheit. Die darauffolgenden Versuche $(30-36)$ mit Expositionszeiten von 0,394 bis 0,41 Sek. und sodann in mehreren in der Tabelle nicht mehr mitgeteilten Versuchsreihen bis über 1 Sek. ergaben auch bei einer Differenz von 0,02 Sek. durchaus unbestimmte Resultate, so dass, soweit aus der Tabelle ein Schluss gezogen werden kann, bei 0,34 Sek. die Grenze gelegen ist, bei welcher eine Differenz von 0,01 Sek. bis 0,02 Sek. noch zu einer für mich wahrnehmbaren Helligkeitsverschiedenheit führte.

Der Untersehied dieses Ergebnisses gegenüber dem der beiden Beobachter Guggenberger und Honigl lässt eine verschiedene individuelle Disposition als Ursache vermuten. Allgemeine Schlüsse in bezug auf die Maximalzeit lassen sich aus Tabelle IV nicht ziehen.

Am 28. Mai vormittags stellte ich mir, da mir keine zweite Versuchsperson zur Verfügung stand, selbst die Sektoren ein und untersuchte Expositionszeiten von 0,28-0,63 Sek. mit Differenzen von 0,018-0,02 Sek. Dieselben führten in allen Fällen zur Beobachtung, dass der länger beleuchtete Halbkreis heller erschien. Dies stand wieder in Widerspruch mit den unbestimmten Angaben der letzten Reihe in Tabelle IV, welche ich deshalb auf eine möglicherweise vorhanden gewesene Indisposition des Beobachters zurückführẹ̣ möchte. 
Es war nun zu erklären, wieso bei einer Differenz von 0,02, resp. 0,02 Sek. fast stets der früher beginnende Halbkreis allen drei Beobachtern Guggenberger, Honigl, Stigler heller ersehien, da doch mit den verwendeten hohen Expositionszeiten die Maximalzeit sicher schon überschritten sein musste. Möglicherweise beherrscht der Eindruck des Lichtreizes, welcher zuerst die Maximalhelligkeit erreicht, in diesen Fällen beim Verschwinden des ganzen Kreises das endgültige Urteil. In welchem Abhängigkeitsverhältnisse stünde dann diese Beeinflussung des Urteiles von der Differenz der Expositionszeiten? Um dies zu ermitteln, versuchte ich es mit der Einstellung grösserer Differenzen, wobei dann deutlich wahrgenommen wurde welcher Halbkreis zuerst erschien.

Bei den in Tabelle V (S. 212) mitgeteilten Versuchen wurde der eine Halbkreis eine beträchtliche Zeit vor dem anderen dargeboten und vom Beobachter währenddessen die vertikale Trennungslinie der beiden Halbkreise fixiert. Die Versuche hatten in dieser Hinsicht eine Ähnlichkeit mit den Dürr'schen, jedoch wurden von Dürr durch einen dunklen Streifen getrennte Reizfelder mit einander verglichen und das eine derselben um eine bedentend grössere Zeit früher dargeboten, nämlich in jedem Falle um mehr als $1 \frac{1 / 2}{2}$ Sek., während bei meinen Versuchen die Differenz immerhin nur $0,0 \dot{5}$ bis $0, \dot{5}$ Sek. betrug. Ich bin mir selbstverständlich bewusst, dass diesen meinen Versuchen die eingangs hervorgehobenen Fehler der möglicherweise auftretenden Induktionswirkung anhaften, und dass deshalb Schlüsse aus Tabelle $\mathrm{V}$ nur mit Reserve gezogen werden dürfen. Diese Schlüsse sind folgende:

Reihe 1-5: Expositionszeiten des länger dauernden Reizes $0, \dot{3}-0, \dot{5}$ Sek., des kürzer dauernden Reizes $0, \dot{2}-0,28$ Sek., Differenzen: $0,08-0, \dot{3}$ Sek.; nach Reihe 4 und 5 würde die Maximalzeit entweder über 0,28 Sek. liegen, oder es wäre bei einer Differenz von 0,08 und 0,2 Sek. noch immer die früher erwähnte Urteilstäuschung vorhanden. Ebenso lässt sich aus Reihe 2 ableiten, dass, da ein Reiz von $0, \dot{5}$ Sek. Dauer heller erschien als ein solcher von $0, \dot{2}$ Sek. Dauer, entweder das Maximum über 0,2 Sek. läge, oder dass bei einer Differenz von 0,3 Sek. noch immer die erwähnte Urteilstäuschung obwalte. In Reihe 6 und 7 zeigt sich, dass der durch $0, \dot{6}$ Sek. dargebotene Halbkreis dunkler ersehien als der durch $0, \dot{2}$ Sek. dargebotene. Hieraus würde folgen, dass das Maximum unter $0, \dot{6}$ Sek. läge, und dass bei der in diesen Fällen angewendeten 
Tabelle V.

\begin{tabular}{|c|c|c|c|c|c|c|c|c|c|c|c|c|c|}
\hline \multirow{3}{*}{$\begin{array}{c}\mathrm{Nr} \\
1\end{array}$} & \multicolumn{2}{|c|}{$\begin{array}{l}\text { Reizdauer } \\
\text { in Sek. }\end{array}$} & \multirow{3}{*}{$\begin{array}{c}\text { Differenz } \\
\text { in Sek. } \\
0, i\end{array}$} & \multirow{2}{*}{\multicolumn{4}{|c|}{$\begin{array}{c}\text { Beobachtungen } \\
\text { von } \\
\text { Guggenberger }\end{array}$}} & \multirow{3}{*}{$\frac{{ }^{\text {Mittel }}}{x}$} & \multirow{2}{*}{\multicolumn{4}{|c|}{$\begin{array}{c}\text { Beobachtungen } \\
\text { von } \\
\text { Stigler }\end{array}$}} & \multirow{3}{*}{$\frac{\text { Mittel }}{r}$} \\
\hline & \multirow{2}{*}{$\frac{\text { links }}{0, \dot{2}}$} & \multirow{2}{*}{$\frac{\text { rechts }}{0,3}$} & & & & & & & & & & & \\
\hline & & & & $l$ & $r$ & $r$ & $r$ & & $r$ & $r$ & $r$ & ? & \\
\hline 2 & 0,2 & $0, \dot{5}$ & $0, \dot{3}$ & & & & & & $r$ & $r$ & $r$ & $r$ & $\eta$ \\
\hline 3 & $0, \dot{3}$ & $0, \dot{2}$ & $0, i$ & $r$ & $l$ & $l$ & $l$ & $l$ & $=$ & $?$ & $l$ & $=$ & ? \\
\hline 4 & 0,36 & 0,28 & 0,08 & $i$ & $l$ & $l$ & $l$ & $l$ & & & & & \\
\hline 5 & 0,48 & 0,28 & 0,2 & $l$ & $l$ & $l$ & $l$ & $l$ & & & & & \\
\hline 6 & $0, \dot{2}$ & $0, \dot{6}$ & $0, \dot{4}$ & $r$ & $=$ & $r$ & $=$ & $?$ & $l$ & 7 & $l$ & $l$ & $l$ \\
\hline 7 & $0, \dot{6}$ & $0, \dot{2}$ & $0, \dot{4}$ & $r$ & $r$ & $r$ & $r$ & $r$ & $r$ & $r$ & $r$ & $r$ & $r$ \\
\hline 8 & 0,52 & 0,68 & 0,16 & $r$ & $r$ & $r$ & $r$ & $r$ & & & & & \\
\hline 9 & 0,4 & 0,68 & 0,28 & $r$ & $r$ & $r$ & $r$ & $r$ & & & & & \\
\hline 10 & $0, \dot{2}$ & $0, \dot{7}$ & $0, \dot{5}$ & $=$ & $l$ & $l$ & $l$ & $l$ & ? & $l$ & $l$ & $l$ & $l$ \\
\hline 11 & $0, \dot{2}$ & $0, \dot{7}$ & $0, \dot{5}$ & $=$ & $l$ & $l$ & $l$ & $l$ & $l$ & $l$ & $l$ & $l$ & $l$ \\
\hline 12 & $0, \dot{7}$ & $0, \dot{2}$ & $0, \dot{5}$ & $r$ & $=$ & $r$ & $r^{*}$ & $r$ & $=$ & $r$ & $r$ & $r$ & $r^{\circ}$ \\
\hline 13 & $0, \dot{7}$ & $0, \dot{2}$ & $0, \dot{5}$ & $=$ & $\eta^{*}$ & $r$ & $r$ & $r$ & & & & & \\
\hline 14 & $0, \dot{2}$ & $0, \dot{7}$ & $0, \dot{5}$ & $=$ & $=$ & $l$ & $=$ & $=$ & $l$ & 7 & $=$ & $=$ & $?$ \\
\hline 15 & $0, \dot{7}$ & 0,2 & $0, \dot{5}$ & $=$ & $r$ & $r$ & $r$ & $r$ & $r$ & $r$ & $r$ & $r$ & $r$ \\
\hline 16 & $0, \dot{7}$ & $0, \dot{2}$ & $0, \dot{5}$ & $l$ & $=$ & $r$ & $=$ & $?$ & $r$ & $r$ & $r$ & $r$ & $r$ \\
\hline 17 & $0, \dot{7}$ & $0, \dot{2}$ & $0, \dot{5}$ & $=$ & $l$ & $=$ & $=$ & $=$ & $=$ & 7 & $l$ & $l$ & $l$ \\
\hline 18 & $0,2 \dot{7}$ & $0, \dot{7}$ & 0,5 & $r$ & $l$ & $=$ & $r$ & $?$ & & & & & \\
\hline 19 & $0,9 \dot{4}$ & $0, \dot{9}$ & $0,0 \dot{5}$ & $r$ & $r$ & $r$ & $r$ & $r$ & & & & & \\
\hline 20 & $0,9 \dot{4}$ & $0, \dot{9}$ & 0,05 & $r$ & $=$ & $r$ & $=$ & $?$ & & & & & \\
\hline 21 & $0, \dot{9}$ & $0,9 \dot{4}$ & 0,05 & $l$ & $l$ & $l$ & $l$ & $i$ & & & & & \\
\hline 22 & $0, \dot{8}$ & $1, \mathbf{i}$ & $0, \dot{2}$ & $r$ & $r$ & $r$ & $r$ & $r$ & & & & & \\
\hline 23 & $0, \dot{8}$ & $1, \mathrm{i}$ & $0, \dot{2}$ & $r$ & $=$ & $=$ & $=$ & $=$ & $=$ & 7 & $l$ & $l$ & $l$ \\
\hline 24 & $1, i$ & $0, \dot{8}$ & $0, \dot{2}$ & $l$ & $=$ & $=$ & $=$ & $=$ & $=$ & $=$ & $r$ & $r$ & $?$ \\
\hline 25 & $1, \dot{1}$. & $1, \dot{1}$ & - & $=$ & $=$ & $=$ & $=$ & $=$ & & & & & \\
\hline 26 & $1,2 \dot{7}$ & 1,8 & $0,0 \dot{5}$ & $r$ & $r$ & $=$ & $r$ & $r$ & & & & & \\
\hline 27 & $1, \dot{3}$ & $1,2 \dot{7}$ & $0,0 \dot{5}$ & $l$ & $l$ & 7 & $l$ & 7 & & & & & \\
\hline 28 & $1, \dot{3}$ & $1, \dot{3}$ & - & $=$ & $l$ & $=$ & $=$ & $=$ & & & & & \\
\hline 29 & $1, \dot{4}$ & 1,3 & $0, i$ & $=$ & $=$ & $=$ & $=$ & $=$ & $?$ & $l$ & $l$ & $=$ & $?$ \\
\hline 30 & 1,3 & $1, \dot{4}$ & $0, \overline{1}$ & $=$ & $=$ & $=$ & $=$ & $=$ & & & & & \\
\hline 31 & $1, \dot{5}$ & $1, \dot{4}$ & 0,1 & $=$ & $=$ & $=$ & $=$ & $=$ & & & & & \\
\hline 32 & $1, \dot{4}$ & $1, \dot{5}$ & $0, i$ & $=$ & $=$ & $=$ & $=$ & $=$ & & & & & \\
\hline
\end{tabular}

Expositionsdifferenz von 0, $\dot{4}$ Sek. der Lichtreiz, welcher sein Maximum früher erreichte, das endgültige Urteil nicht mehr beherrschte. Reihe 8 und 9 zeigen aber wieder, dass ein Reiz von 0,68 Sek. heller erscheint als ein soleher von 0,4 , resp. 0,52 Sek. Darnach müsste ein Reiz in der Dauer von 0,67 Sek. bedeutend heller erscheinen als ein solcher von $0, \dot{2}$ Sek. (Reihe 6 und 7). Da es sich aber in Wirklichkeit umgekehrt verhält, so muss man schliessen, dass die grössere Helligkeit des länger dauernden Reizes in Reihe 8 und 9 durch andere Umstände bedingt ist, möglicherweise dadurch, dass eine 
Über die Unterschiedsschwelle im aufsteig. Teile einer Lichtempfindung. 213

Differenz von 0,28 , resp. 0,16 Sek. nicht genügte, um das durch die zuerst aufgetretene Maximalhelligkeit des länger dauernden Reizes bestimmte Urteil zu ändern. Das Maximum ist aber bei $0, \dot{6}$ Sek. bereits übersehritten, da der Halbkreis bei $0, \dot{2}$ Sek. Expositionszeit heller erscheint als bei $0, \dot{6}$ sek.

Aus den für beide Beobachter übereinstimmenden Resultaten der Reihen 10-17 geht hervor: der durch $0, \dot{7}$ Sek. dargebotene Halbkreis erscheint immer dunkler als der während $0, \dot{2}$ Sek. dargebotene; hingegen erscheint der durch $0, \dot{7}$ Sek. dargebotene Halbkreis heller als ein durch $0, \dot{5}$ Sek. dargebotener (Reihe 17). Demnach müsste derselbe viel heller erscheinen als ein Halbkreis, welcher nur durch $0, \dot{2}$ Sek. dargeboten wurde. Da sich dies aber umgekehrt verhält, so ergibt sich hieraus wieder der Schluss, dass das Maximum bei $0, \dot{7}$ Sek. bereits überschritten wäre, da ein während dieser Zeit dargebotener Halbkreis dunkler erscheint als ein solcher von $0, \dot{2}$ Sek., dass aber eine Expositionsdifferenz von $0, \dot{2}$ Sek. noch nicht hinreicht, um das durch den zuerst maximal hell gewordenen Halbkreis bestimmte Urteil zu ändern.

Reihen 19-27 zeigen wieder, dass bei Expositionszeiten von $0,9 \dot{4}-1, \dot{3}$ Sek. der um $0,0 \dot{5}-0, \dot{2}$ Sek. früher dargebotene Halbkreis stets als heller empfunden wird. Dies scheint mir auch wieder meine Vermutung zu bestätigen, dass der zuerst maximal erhellte Halbkreis das Urteil auch beim Verschwinden des ganzen Halbkreises noch beeinflusse, dass also der erste Eindruck bei einer reitlichen Differenz der beiden Reizflächen bis zu $0, \dot{2}$ Sek. das endgültige Urteil bestimme. Denn es ist doch auf keinen Fall anzunehmen, dass bei 1,27 Sek. das Maximum noch immer nicht erreicht wäre und aus diesem Grunde der durch $1, \dot{3}$ Sek. dargebotene Halbkreis heller erscheine.

Reihen 29 bis 32 zeigen, dass bei Expositionsdauern von $1, \dot{3}$ bis $1, \dot{5}$ Sek. eine zeitliche Differenz von $0, \dot{1}$ Sek. überhaupt zu keiner Unterscheidung der beiden Reizfeldhelligkeiten mehr führt.

Aus dem Vorhergehenden kann daher geschlossen werden:

Bis zu einer Expositionszeit von 0,34 Sek. reichte eine zeitliche Differenz von $0,01 \dot{6}$ Sek. in allen Fällen hin, um den länger belichteten Halbkreis als heller zu beurteilen.

Wird die Expositionszeit grösser als 0,34 Sek., so wird bei einer Differenz von $0, \dot{1}$ Sek. die Helligkeit der beiden Halbkreise nicht mehr unterschieden, sondern das Urteil über das Helligkeits- 
verhältnis wird ganz unbestimmt (Tab. IV). Beträgt aber die Differenz der Expositionsdauer 0,02 Sek. (Tab. II u. III), so wird bis zu einer Expositionszeit von mindestens 0,68 Sek., von einem Beobachter ( $\mathrm{H} \circ \mathrm{nigl}$ ) sogar bis zu einer Expositionszeit von 1, $\dot{3}$ Sek., der früher erscheinende Halbkreis im Momente des Verschwindens des ganzen Kreises als heller bezeichnet. Desgleichen wird bis zur gleichen Expositionszeit von 1, $\dot{3}$ Sek. der früher erscheinende Halbkreis als heller bezeichnet, wenn die Differenz bis zu $0,0 \dot{5}$ Sek. steigt. Wird die Differenz weiter auf $0, \dot{2}$ Sek. erböht, so wird ebenfalls noch in der Hälfte der Fälle (Tab. V, 17, 22) der länger dauernde Lichtreiz, in anderen Fällen (Tab. V, 23, 24, Beobachter Stigler) der kürzer dauernde als heller bezeichnet; in einigen Fällen werden die beiden Lichtreize als gleich hell bezeichnet (Tab. V, 23, 24, Gu g g e n berge r). Wird aber die Differenz bis zu $0, \dot{4}$ Sek. oder darüber gesteigert (Tab. V, 6, 7, 10-16), so erscheint ein Lichtreiz von der Dauer von $0, \dot{6}-0, \dot{7}$ Sek. dunkler als ein solcher von $0, \dot{2}$ Sek. Daraus ergibt sich, dass die Maximalhelligkeit bei einer geringeren Expositionszeit als $0, \dot{6}$ Sek. erreicht werden muss. Bezüglich der Differenzen ergibt sich aus Tab. I-V folgendes Verhalten:

"Es gibt für untermaximale Lichtreize eine bestimmbare Schwellendifferenz, welche eben noch hinreicht, um den kürzer exponierten Lichtreiz als dunkler zu empfinden. Wird die Differenz der Expositionsdauern zweier untermaximaler Vergleichsreize geringer als der Schwellenwert gewählt, so wird das Urteil über das Helligkeitsverhältnis der beiden Vergleichsreize unbestimmt. Wird die Differenz überschwellig gewählt, so ist der Helligkeitsunterschied zwischen den beiden untermaximalen Vergleichsreizen deutlicher. Die Schwelle der zeitlichen Differenz steigt mit der Grösse der Expositionsdauern (Tab. I), in einer im dritten Abschnitte näher zu untersuchenden Weise. Steigt die Differenz bis auf $0,02-0,0 \dot{5}$ Sek., so erseheint der länger dauernde Vergleichsreiz bei der hier verwendeten Versuchsanordnung bis zu weit über das Maximum steigenden Expositionsdauern (mindestens $1, \dot{3}$ Sek.) heller als der kürzer dargebotene. Wird die Differenz über $0, \dot{2}$ Sek. erhöht, so erscheint in einigen Fällen, bei einer Erhöhung der Differenz bis auf $0, \dot{4}$ resp. $0, \dot{5}$ Sek. in allen Fällen der übermaximale Lichtreiz dunkler als der dem Maximum näherstehende untermaximale Lichtreiz." "“

Dieses eigentümliche Verhalten sehe ich auch teilweise in 
Über die Unterschiedsschwelle im aufsteig. Teile einer Lichtempfindung. 215

Kunkel's und Petrèn's Angaben bestätjgt, welche einen um 0,2 Sek. länger dauernden Lichtreiz auch bei den böchsten von ibnen verwendeten übermaximalen Expositionszeiten als heller wahrnahmen. Die Exner'schen Versuchsergebnisse stehen damit in Widerspruch, da dieser bei einer Differenz von etwa $1 / 60$ Sek. den übermaximalen Lichtreiz dunkler wahrnahm als den angeblich im Maximum stehenden kürzer dauernden. $O b$ dies auf der verschiedenen Versuchsanordnung oder auf verschiedener individueller Disposition der Beobachter beruhte, kann ich nicht feststellen, jedoch sei daran erinnert, dass Kunkel zu seinen Ergebnissen mit der Exner'schen Versuchsanordnung gelangte.

$\mathrm{Zu}$ erwarten wäre, wie auch Petrèn dachte, dass ein übermaximaler Lichtreiz von dem maximalen oder einem dem Maximum näher stehenden sich, falls die Differenz der Expositionszeiten entsprechend gross ist, durch geringere Helligkeit, oder, falls jenes nicht der Fall ist, gar nicht unterscheide. Tatsächlich kann der ühermaximale Lichtreiz von einem dem Maximum näher stehenden nicht unterschieden werden, wenn die Differenz unter eine bestimmte Grenze fällt, (wahrscheinlich 0,02 Sek.); bei einer grösseren Differenz (sicherlich von $0,0 \dot{5}$ Sek. an) erscheint er aber immer heller als der kürzer dauernde, und erst bei einer Differenz von mindestens $0, \dot{2}$ Sek. tritt das theoretisch erwartete Verhalten auf, dass der übermaximale Lichtreiz dunkler erscheint als der dem Maximum näher stehende.

Dieses paradoxe Verhalten bedarf einer Erklärung. Ich glaube, dass es sich bei objektiv gleichen Helligkeiten, wenn einer der beiden oder beide Vergleichsreize übermaximal sind, darum handelt, dass der Vergleichsreiz, welcher zuerst das Maximum seiner Helligkeit erlangt, hierdurch das Vergleichsurteil des Beobachters bestimmt. Ist die zeitliche Differenz der beiden Reize zu gering, so folgt das Maximum des kürzer dauernden Reizes so rasch dem des länger dauernden (falls beide übermaximal sind), dass eine getrennte Wahrnehmung nicht mehr stattfindet und das Urteil daher unbestimmt lautet, indem der Eindruck der beiden benachbarten Maximalreize in der Beurteilung des Beobachters verschmilzt. Ist die Differenz grösser (wahrscheinlich $0,02-0,2$ Sek.), so beherrscht der erste Eindruck des seine Maximalhelligkeit früher erreichenden Lichtreizes das Vergleichsurteil des Beobachters, so dass dieser nicht mehr imstande ist, die Umkehr der Reizzustände beim gleichzeitigen Ver- 
schwinden der beiden Lichtreize wahrzunehmen. Ist die Differenz noch grösser (über 0, $\dot{2}$ Sek.), so ist der Beobachter wieder imstande, die Umkehr der anfänglichen Helligkeitsverhältnisse beim Verschwinden der beiden Reize wahrzunehmen, da sein Urteil zu dieser Zeit bereits nicht mehr von dem ersten Eindrucke des maximal hellen, länger dauernden Lichtreizes beherrscht wird.

Es scheint demnach, dass die Maximalzeit mit der zuerst von Exner angewendeten Versuchsanordnung, welche im Prinzip auch Petrèn's und meiner Arbeit zugrunde liegt, nicht direkt bestimmbar ist. Jedocb wird es vielleicht möglich sein, dieselbe aus dem Verhalten der zeitlichen Unterschiedssehwelle, namentlich in Kombination mit der Umgrenzung des Maximums durch überschwellige Differenzen von mebr als $0, \dot{2}$ Sek, wobei der Helligkeitsumschlag des übermaximalen Reizes wahrnehmbar ist, zu erschliessen. Nach dem bisherigen ist zu erwarten, dass, solange noch eine Differenz von weniger als 0,02 Sek. zu einem wahrnehmbaren Helligkeitsunterschied der beiden Vergleichsreize führt, die Maximalzeit noch nicht erreicht worden ist. Jedenfalls müsste noch eine grössere Reihe von Versuchen dartun, ob diese Vermutung berechtigt ist ${ }^{1}$ ).

Ehe ich mich der genauen Untersuchung der zeitlichen Unterschiedsschwelle zuwendete, versuchte ich noch die von $\mathrm{Char}$ pentier und Martius angewendete Versuchsanordnung zur Ermittlung der Maximalzeit mit Darbietung eines konstanten Vergleichs-

1) Angesichts unserer geschilderten Versuchsergebnisse und Schlüsse erscheint es auffällig, dass $B \ddot{c} \mathrm{chner}$ mit seiner Versuchsanordnung so plötzliche und bedeutende postmaximale Schwankungen, wie sie sich in seinen Kurven, ganz besonders in Fig. 7 (l. c. S. 14), zeigen, feststellen konnte. Es wird leider von $B$ ü $c h n$ er nicht erwähnt, ob ihm beim Vergleiche eines übermaximalen Normalreizes mit dem (stets $100 \sigma$ währenden und nur in seiner Intensität variierten) Vergleichsreize nicht kurz (wie aus Fig. 7, 1. c., ersichtlich, etwa 0,02 Sek.) vor dem Verschwinden der beiden Vergleichsfelder der Normalreiz auffallend heller erschienen ist als der Vergleichsreiz, und ob er die plötzliche Verdunkelung des ersteren für sich wahrgenommen hat; ob also bei der Darbietung eines die Maximalzeit um 0,02 Sek. überdauernden Reizes eine einheitliche Gesamtwirkung der durch denselben erregten Helligkeitsempfindung eingetreten ist, oder ob letztere in zwei Teile, das hellere Maximum und einen dunkleren abfallenden. Teil, zerlegt erscheint, wie aus seinen Angaben wohl indirekt geschlossen werden muss. Wie erwähnt, konnten weder Kunkel, noch Petrèn, noch wir mit unserer Versuchsanordnung die Helligkeitsempfindung in so knapper Nähe binter dem vermutlichen Maximum analysieren. 
reizes. $\mathrm{Zu}$ diesem Zwecke wurde die langsame Scheibe unserer Versuchsanordnung entfernt und die rascher gehende mit Hilfe des Vorgeleges wieder auf' eine Umdrehungszeit von 4 Sek. eingestellt. Von ihr wurde aber der die einzelnen Sektoren begrenzende Kreisring entfernt, so dass der rechtsseitige Halbkreis konstant beleuchtet blieb. Der linke Halbkreis wurde nach Maassgabe der Grösse der eingestellten inneren Sektoren der Scheibe beliebige Zeit beleuchtet. Von den mit dieser Versuchsanordnung ausgeführten Beobachtungen teile ich einige in Tab. VI mit.

Tabelle VI.

Beobachter Stigler. 28. Mai. Alle 4 Sek. ein Reiz, Versuchsanordnung nach Charpentier-Martius mit Darbietung eines konstanten Vergleichsreizes (rechts).

\begin{tabular}{|c|c|c|c|c|c|c|c|}
\hline \multirow{3}{*}{$\frac{\text { Nummer }}{1}$} & \multicolumn{2}{|c|}{ Dauer d. Lichtreizes in Sek. } & \multirow{2}{*}{\multicolumn{4}{|c|}{ Beobachtungen }} & \multirow{3}{*}{$\frac{\text { Mittel }}{r}$} \\
\hline & \multirow{2}{*}{$\frac{\text { links }}{0,05}$} & \multirow{2}{*}{$\frac{\text { rechts }}{4-20}$} & & & & & \\
\hline & & & $r$ & $r$ & $r$ & $r^{*}$ & \\
\hline 2 & $0,07 \dot{2}$ & $4-20$ & $=$ & $=$ & $=$ & $\therefore=$ & $=$ \\
\hline 3 & 0,083 & $4-20$ & $l$ & $\ell$ & $l$ & $l$ & $l$ \\
\hline 4 & $0, \dot{1}$ & $4-20$ & $l$ & $l$ & $l$ & $l$ & $l$ \\
\hline 5 & $0,1 \dot{6}$ & $4-20$ & $l$ & $l$ & $l$ & 7 & $l$ \\
\hline 6 & $0, \dot{2}$ & $4-20$ & $l$ & $l$ & $l$ & $l$ & $l$ \\
\hline 7 & $0,2 \dot{7}$ & $4-20$ & $l$ & $l$ & $l$ & $l$ & $l$ \\
\hline 8 & $1, \dot{3}$ & $4-20$ & $=$ & $?$ & $=$ & $?$ & $?$ \\
\hline 9 & $1, \dot{7}$ & $4-20$ & $=$ & $=$ & $=$ & $=$ & $=$ \\
\hline
\end{tabular}

Gleich Martius kann ich bestätigen, dass die Beurteilung des Helligkeitsverhältnisses bei dieser Versuchsanordnung (konstanter Vergleichsreiz) weit geringere Schwierigkeiten darbietet als bei der Verwendung von ganz geringen zeitlichen Differenzen. Leider ist die Methode trotzdem für die Bestimmung der Maximalzeit als gänzlich ungeeignet zu betrachten. Aus Tab. VI geht hervor, dass der linke Halbkreis bei einer Expositionsdauer von $0, \dot{5}$ Sek. noch dunkler, bei 0,07 Sek. bereits gleich bell, und bei grösseren Expositionszeiten bis mindestens $0,2 \dot{7}$ Sek. deutlich heller, bei viel längeren Expositionszeiten von 1,3 Sek. aufwärts aber wieder gleich hell wie der rechtsseitige Halbkreis erschien, der konstant dargeboten wurde, und dessen vertikalen Durchmesser an der Grenze der beiden Vergleichsfelder der Beobachter fixierte. Zwischen $0,2 \dot{7}$ und $1, \dot{3}$ Sek. sind keine Einstellungen vorgenommen worden, so dass ich über diesen Zwischenraum keine Angaben machen kann. Wenn man dieser Versuchs- 
anordnung Glauben schenkte, so betrüge die Maximalzeit in dem von mir untersuchten Falle 0,072 Sek.; Charpentier fand sie bei $0,012-0,062$, Martius bei $0,013-0,093$, so dass meine Versuchsergebnisse damit hinlänglich übereinstimmen würden. Im übrigen habe ich mich über diese Versuchsanordnung bereits eingangs geäussert.

\section{Teil. Die zeitliche Lnterschiedsschwelle.}

Um die zeitliche Unterschiedsschwelle genauer zu untersuchen, wurde die langsam rotierende Scheibe wieder eingeschaltet, die schneller rotierende in der eingangs bezeichneten Kombination angewendet und der Motor ohne Vorgelege so eingestellt, dass die rascher gehende Scheibe in 36 Sek. 100 Umdrehungen machte; damit wurde eine bequeme Ablesung der Zeit an der Gradteilung bezweckt, da $1^{\circ}$ genau einer Zeit von 0,001 Sek. entsprach. Alle 25 Umdrehungen der schnellen Scheibe erfolgte ein Lichtreiz, also alle 9 Sek. Da je vier Lichtreize hintereinander beobachtet wurden, so betrug die Zeit, während welcher der Beobachter im Dunkeln sass, 36 Sek. Die Stromunterbrechungsuhr gab alle 3 Sek. ein kurzes Glockenzeichen. Da der grösste einstellbare Sektor der schnellen Scheibe $170^{\circ}$ betrug, so konnten mit dieser Anordnung Zeiten bis zu 0,17 Sek. untersucbt werden.

Als Beispiel des Untersuchungsvorganges führe ich Tab. VII an.

Tabelle VII.

Beobachter: Guggenberger. 19. Juni 1907.

\begin{tabular}{|c|c|c|c|c|c|c|c|c|}
\hline \multirow{2}{*}{ Nr. } & \multicolumn{2}{|c|}{$\begin{array}{l}\text { Dauer des Lichtreizes } \\
\text { in Sek. }\end{array}$} & \multirow{2}{*}{$\begin{array}{l}\text { Differenz } \\
\text { in Sek. }\end{array}$} & \multirow{2}{*}{\multicolumn{4}{|c|}{ Beobachtungen }} & \multirow[t]{2}{*}{ Mittel } \\
\hline & links & rechts & & & & & & \\
\hline 1 & 0.015 & 0,013 & 0.002 & $r$ & $l$ & $l$ & $l$ & $l$ \\
\hline 2 & 0,013 & 0.015 & 0,002 & $=$ & $r$ & $r$ & $r$ & $r$ \\
\hline 3 & 0,014 & 0,015 & 0,001 & $r$ & $r$ & $r$ & $r$ & $r$ \\
\hline 4 & 0,014 & 0,015 & 0,001 & $r$ & $r$ & $r$ & $r$ & $r$ \\
\hline 5 & 0,015 & 0,015 & - & $?$ & $i$ & $r$ & $r$ & $?$ \\
\hline 6 & 0,015 & 0,014 & 0,001 & 7 & $l$ & $l$ & $l$ & $l$ \\
\hline 7 & 0,015 & 0,014 & 0,001 & $l$ & $r$ & $l$ & $l$ & $l$ \\
\hline 8 & 0,015 & 0,014 & 0,001 & $r$ & $l$ & $i$ & $r$ & ? \\
\hline $\begin{array}{l}0 \\
9\end{array}$ & $\begin{array}{l}0,010 \\
0,015\end{array}$ & 0,014 & 0,001 & 7 & $l$ & $l$ & 7 & $i$ \\
\hline 10 & 0,014 & 0,015 & 0,001 & $l$ & $r$ & $l$ & $r$ & $?$ \\
\hline 11 & 0,014 & 0,015 & 0,001 & $r$ & $r$ & $r$ & $r$ & $r$ \\
\hline 12 & 0,0145 & 0,015 & 0,0005 & $r$ & $r$ & $r$ & r & $r$ \\
\hline 13 & 0,0145 & 0,015 & 0,0005 & $i$ & $r$ & $i$ & 2 & $l$ \\
\hline 14 & 0,015 & 0,0145 & 0,0005 & $r$ & ? & $r$ & $r$ & $r$ \\
\hline
\end{tabular}

Resultat: Zeitliche Unterschiedsschwelle bei Expositionszeit von 0,015 für Guggenberger $=0,001$ Sek. 
Das Prinzip der Untersuchung war folgendes:

Es wurde zuerst immer eine solche zeitliche Differenz eingestellt, dass daraus ein deutlicher Helligkeitsunterschied resultierte. (Nr. 1 und 2 Tab. VII.) Diese Differenz wurde sodann so weit vermindert, bis das Urteil des Beobachters im Durchschnitt unbestimmt oder falsch lautete. (Nr. 13, 14.) Die geringste Differenz, bei der im Durchschnitt noch der länger dargebotene Halbkreis als heller bezeichnet wurde, wurde als zeitliche Unterschiedsschwelle in Tab. VIII eingetragen. Die Versuche fanden meist am Nachmittage statt; zu Beginn jeder Sitzung wurden während etwa $10 \mathrm{Min}$. Finübungsversuche vorgenommen, deren Resultate in unsere Tabellen nicht eingetragen wurden, weil es sich gezeigt hatte, wie leicht erklärlich, dass die ersten Versuche immer viel zu grosse Unterschiedsschwellen zutage förderten. Die Anzahl von Versuchen, welche zur Ermittlung eines gültigen Durchschnittsresultates erforderlich waren, war bei den geringeren Expositionsdauern - wie in Tabelle VII - kleiner als bei den grösseren und im ganzen stets von den eingangs erwähnten persönlichen Verbältnissen des Beobachters abhängig.

Tabelle VIII.

\begin{tabular}{|c|c|c|c|c|c|}
\hline \multirow{2}{*}{$\begin{array}{c}\text { Expositions- } \\
\text { zeit des länger } \\
\text { dauernden } \\
\text { Reizes in Sek. }\end{array}$} & \multicolumn{2}{|c|}{$\begin{array}{l}\text { Zeitliche Unterschieds- } \\
\text { schwelle in Sek. }\end{array}$} & \multirow{2}{*}{$\begin{array}{c}\text { Expositions- } \\
\text { zeit des länger } \\
\text { daueruden } \\
\text { Reizes in Sek. }\end{array}$} & \multicolumn{2}{|c|}{$\begin{array}{l}\text { Zeitliche Unterschieds- } \\
\text { schwelle in Sek. }\end{array}$} \\
\hline & $\begin{array}{l}\text { Guggen- } \\
\text { berger }\end{array}$ & Stigler & & $\begin{array}{c}\text { Guggen- } \\
\text { berger }\end{array}$ & Stigler \\
\hline 0,01 & $\begin{array}{l}\text { Nicht mehr } \\
\text { wahr- } \\
\text { genommen }\end{array}$ & 0,0005 & $\begin{array}{l}0,12 \\
0,13 \\
0,14\end{array}$ & $\begin{array}{l}0,006 \\
0,007 \\
0,007\end{array}$ & $\begin{array}{l}0,007 \\
0,007 \\
\end{array}$ \\
\hline 0,015 & 0,001 & 0,0015 & 0,15 & 0,007 & 0,008 \\
\hline 0,02 & 0,002 & 0,002 & 0,16 & 0,008 & 0,008 \\
\hline 0,03 & 0,003 & 0,00 & 0,17 & 0,008 & - \\
\hline 0,04 & 0,003 & 0,003 & 0,18 & - & 0,008 \\
\hline 0,05 & 0,0035 & 0,003 & 0,2 & 0,008 & 0,006 \\
\hline 0,06 & 0,004 & 0,0035 & 0,24 & 0,008 & 0,012 \\
\hline 0,07 & 0,005 & 0,004 & 0,28 & 0,008 & $0,011(0,016 ?)$ \\
\hline 0,08 & 0,005 & 0,005 & 0,3 & 0,013 & _ \\
\hline 0,09 & 0,005 & 0,005 & 0,32 & 0,016 & $0,011(?)$ \\
\hline 0,1 & 0,005 & & 0,34 & 0,016 & 0,011 (?) \\
\hline 0,11 & 0,005 & 0,0055 & 0,36 & $0,02(?)$ & - \\
\hline
\end{tabular}

Im allgemeinen konnte die Sitzung eines Beobachters ganz gut eine halbe Stunde betragen, ohne dass er wirklich ermüdete. Zur Untersuchung grösserer Zeiten als 0,17 Sek. wurde die Umdrehungszeit der raschen Scheibe verdoppelt, resp. vervierfacht. Die Pausen zwischen den einzelnen Reizen betrugen dann 18, bzw. 36 Sek. 
Da im letzteren Falle der Beobachter durch 4 mal $36=144$ Sek. im Dunklen hätte bleiben müssen, was für die Adaptation nicht gleichgültig gewesen wäre, so wurde die langsame Scheibe in diesem Falle mit zwei gegenüberliegenden Ausschnitten versehen, so dass während einer Umdrehung der langsamen Scheibe zwei Lichtreize stattfanden und demnach der Beobachter nur während 72 Sek. in den Dunkelkasten zu blicken hatte. Es wurden mit dieser Versuchsanordnung im Juni und Juli 1907 von Guggenberger und mir 2560 Versuchsreihen zu je vier Beobachtungen durchgeführt. Das Ergebnis derselben zeigte einen Übelstand, nämlich den grossen Einfluss der Übung, so dass die Unterschiedsschwelle gegen Ende unserer Beobachtungszeit deutlich unter die zu Beginn derselben gefundenen Werte herabsank. Ich habe deshalb auch später die anfangs vorgenommenen Untersuchungen, soweit es unsere Zeit erlaubte, wiederbolt. Die endgültigen Ergebnisse sind in Tab. VIII mitgeteilt; jedoch sind die für die höchsten Expositionsdauern gefundenen zeitlichen Schwellendifferenzen nicht ganz sicher, da sich bei Wiederholung dieser Reihen an verschiedenen Tagen Variationen bis zu einem Spielraume von 0,05 Sek. zeigten. Eine Fortsetzung der Reihe über 0,34 Sek. hinaus schien mir überflüssig, da, wie ich im II. Teile auseinandergesetzt habe, eine Differenz von 0,02 Sek. bei unserer Versuchsanordnung immer den länger dauernden Lichtreiz heller erscheinen lässt. Hingegen wäre es notwendig, zu untersuchen, ob die zeitliche Untersehiedsschwelle bei Expositionszeiten von 0,34 Sek. aufwärts sich nicht doch noch als geringer als 0,02 Sek. erwiese. Die allerdings sehr grosse Anzahl der von uns hierüber angestellten Versuche kann angesichts der erwähnten Schwankungen ihrer Ergebnisse noch nicht als hinreiclend bezeichnet werden.

Bezüglich der Maximalzeit kann aus unserer Tabelle der zeitlichen Unterschiedsschwelle wiederum nichts ganz Sicheres geschlossen werden, einerseits wegen der erwähnten Unsicherheit der drei letzten Reihen der Tab. VIII, andererseits deshalb, weil ich nicht imstande bin, $z \mathfrak{u}$ entscheiden, $o b$ die in denselben festgestellten zeitlichen Unterschiedsschwellen auf tatsächlicher Helligkeitsverschiedenheit zweier untermaximaler Lichtreize oder ob die Empfindung der grösseren Helligkeit des länger dauernden Reizes vielleicht auch schon auf der Beeinflussung des Vergleichsurteiles durch den zuerst maximal gewordenen Reiz beruht. Wahrscheinlich ist aber letzteres 
Über die Unterschiedsschwelle im aufsteig. Teile einer Lichtempfindung. 221

nicht der Fall, da sich aus den früheren Tabellen ergibt, dass erst bei einer Differenz von 0,02 Sek. die erwähnte "Urteilstäuschung" auftritt. Demnach würde die Maximalzeit der hier verwendeten Lichtreize grösser als 0,34 Sek., aber, wie sich früher ergab, kleiner als $0, \dot{6}$ Sek. sein.

Nach Tabelle VIII habe ich die Kurven in Fig. 3 konstruiert, wobei als Abszissen die Expositionszeiten des länger dauernden Reizes in Hundertstelsekunden, als Ordinaten die zeitliche Unterschiedsschwelle in Tausendstelsekunden verzeichnet erscheinen. Die

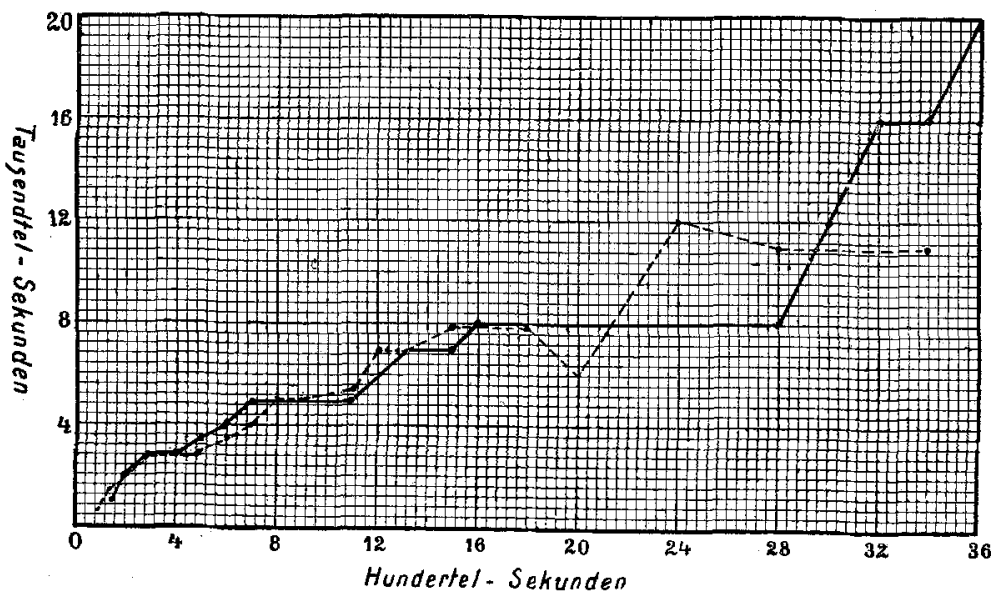

Kurve G's

Kurve St's.

Fig. 3. Abszisse: Expositionszeiten des länger dauernden Reizes, Ordinate: Zeitliche Unterschiedsschwellen.

Kurve Stigler's ist nur bis zur Expositionszeit von 0,24 Sek. als genagend sicher zu betrachten, da sich bei den höheren Expositionszeiten bereits Schwankungen der Unterschiedsschwelle bis zu 0,005 Sek. einstellten.

Auffallend erscheinen drei Oszillationen, die sich in beiden Kurven nahezu decken und sehr gut mit den drei Oszillationen übereinstimmen, welche an allen Büchner'schen Kurven des Helligkeitsanstieges zutage treten.

Die beiden Kurven zeigen ein nahezu übereinstimmendes Ansteigen der Unterschiedsschwelle bis zu 0,008 Sek. bei einer Exposition von 0,16 Sek. Hernach verläuft die Kurve Guggenberger's geradlinig bis zur Expositionszeit von 0,28 Sek., um dann plötzlich 
anzusteigen. Dieses Ansteigen ist bei Stigler bereits etwas früher $\mathrm{zu}$ bemerken. Die Fortsetzung der Kurve über die höchste eingezeichnete Expositionszeit von 0,36 Sek. hinaus würde einen geradlinigen Verlauf in der Höhe von 0,02 Sek. ergeben, wie aus den früheren Tabellen und meinen darauf bezüglichen Erörterungen hervorgeht. Die geringste Expositionsdauer, die wir untersuchten, betrug 0,01 Sek., wobei Guggenberg er bereits gar kein Aufleuchten der Reizfläche mehr bemerken konnte, während es mir noch gelang, einen deutlichen Helligkeitsunterschied der beiden Halbkreise bei einer Differenz von 0,0005 Sek: wahrzunehmen. Petrèn hat noch viel geringere Expositionszeiten untersucht; offenbar konnte er das wegen der weit grösseren Helligkeit seiner Reizflächen. Die zeitlichen Unterschiedsschwellen Petrèns waren aber durchaus grösser als die unseren. Bei einer Expositionsdauer von 0,01 Sek. fand Petrèn die Schwellendifferenz bei 0,0012 Sek., bei einer höheren Expositionszeit bis zu etwa 0,1 Sek. im Mittel bei 1/10, von 0,1 Sek. aufwärts bei 1/12 der Expositionsdauer. Aus unseren Kurven aber ergibt sich, dass das Verhältnis der Schwellendifferenz zur Expositionsdauer bei 0,01 Sek. Expositionsdauer (Stigler) mit 20, bzw. bei einer Expositionsdauer von 0,015 Sek. (Guggenberger) mit 15 beginnt, sodann bis zur Expositionsdauer von 0,03 Sek. auf 10 herabsinkt, um dann, allmählich ansteigend, bei der Expositionsdauer von 0,1 Sek. in beiden Kurven wieder die Zahl $20 \mathrm{zu}$ erreichen. Von 0,16 Sek. Expositionszeit an steigt das Verhältnis der Schwellendifferenz zur Expositionszeit wieder an und erreicht für Guggenberger sein Maximum bei der Expositionszeit von 0,28 Sek, mit der Zahl $35\left(=\frac{0,28}{0,008}\right)$, für Stigler bei der Expositionszeit von 0,2 Sek mit der Zahl $33\left(=\frac{0,2}{0,006}\right)$. Petrèn gedachte in seiner Kurve ein Bild der zeitlichen Unterschiedsempfindlichkeit zu geben, indem er als Abszisse die Expositionszeiten und als Ordinate das Verbältnis der letzteren zur zeitlichen Differenz wählte. Er nahm also das Verhältnis von zeitlicher Unterschiedssehwelle zur Expositionszeit als Ausdruck der zeitlichen Unterschiedsempfindlichkeit an. Ich kann dem nicht beistimmen: denn nur wenn das Ansteigen der Liehtempfindung geradlinig erfolgte, wäre die Expositionsdauer als Maass der Empfindungsstärke verwendbar, und nur dann könnte das Verbältnis von zeitlicher 
Untersehiedssehwelle zur Expositionsdauer. als Maass der zeitlichen Unterschiedsempfindlichkeit gelten. Kunkel's und Charpentier's Meinung war, dass das Ansteigen der Lichtempfindung geradlinig erfolge; die meisten übrigen Autoren aber nehmen an' dass auf ein anfänglich geradliniges Ansteigen ein allmähliches Absinken der Kurve gegen die Abszisse folge; namentlich hat dies Martius aus seinen Versuchen geschlossen. Wirth will sogar in seinem erwähnten Referate die Differenzen in den Angaben der Autoren über die Maximalzeit durch die grosse Ausdehnung des nach seiner Meinung sehr flachen Gipfels der Lichtempfindungskurve erklären.

Die erwähnten Untersuchungen Bächner's ergeben nun einen wellenförmigen Verlauf des Anstieges der Helligkeitsempfindung, und daraus geht hervor, dass die zeitliche Unterschiedssehwelle zur Unterschiedsempfindlichkeit in keinem bestimmten, sondern in einem der wellenförmigen Kurve entsprechend wechselnden Verhältnisse steht.

Sicher zeigen indessen unsere Kurven, was auch P etrèn aus den seinigen geschlossen hat: dass die zeitliche Unterschiedsempfindlichkeit mit der Grösse der Expositionsdauer steigt, und dass sie somit dem Weber'schen Gesetz nur streckenweise folgt. Es verhält sich somit die zeitliche Unterschiedsempfindlichkeit des fovealen Anteiles des Sehorganes so, wie es auch Garte $\mathbf{n}^{\mathbf{l}}$ ) von der Wahrnehmung von Intensitätsveränderungen der Beleuchtung des ganzen Gesichtsfeldes gefunden hat: dass „mit steigender Belastung die relative Empfindlichkeit steigt".

1) Am Schlusse der zitierten Abhandlung. 